\title{
COVID-19: stress-testing non-financial companies: a macroprudential perspective. The experience of Poland
}

\author{
Natalia Nehrebecka ${ }^{1,2} \mathbb{D}$ \\ Received: 10 June 2020 / Revised: 23 November 2020 / Accepted: 25 November 2020 / \\ Published online: 3 March 2021 \\ (c) Eurasia Business and Economics Society 2021
}

\begin{abstract}
The main purpose of this article is to detail and supply a stress-testing framework at the individual level that investigates the impact of COVID-19 scenarios on nonfinancial firms' probability of default as regards domestic and foreign-currency debt (a so-called new micro stress-test). The test addresses both the uniform and the asymmetrical transmission of shocks, in relation to sizes of firms and sectors of their activity. To allow for the running of micro stress-tests of this kind, a general model was constructed using a two-step approach comprising a microeconomic model and a macroeconomic module. Accompanying empirical analysis was based on individual data from different sources (relating to the years 2007-2020), i.e. prudential reporting, business registration, financial and behavioral data and balances of payments. In line with the factor of company size, the quality of loan portfolios is shown to deteriorate on the balance sheets of banks in all segments in the case of a negative scenario (for large and medium-sized enterprises the probability of default increases 1.5 -fold, for small ones over threefold). While almost all industries will experience the impact of COVID-19, sections being hit particularly hard will involve services that, due to the ban on gatherings of people and the recommendation to avoid crowds, will lose most of their revenue and will fail to make up for this loss in the future.
\end{abstract}

Keywords COVID-19 · Micro stress test · Probability of default $\cdot$ Default rate $\cdot$ Macroprudential perspective

Natalia Nehrebecka

nnehrebecka@wne.uw.edu.pl; Natalia.Nehrebecka@nbp.pl

1 Faculty of Economic Sciences, Warsaw University, Długa 44/50, 00-241 Warsaw, Poland

2 National Bank of Poland, Świętokrzyska 11/21, 00-919 Warsaw, Poland 


\section{Introduction}

Initially, the COVID-19 epidemic affecting China accounted for differences in international value chains that were only of limited size. However, that local epidemic has since assumed pandemic form, transforming into a major economic shock-factor around the world, when it comes to the transactions of both businesses and consumers. In contrast, all previous global economic changes (not least the crisis of 2008-2009) had a financial background.

Credit risk threatens the stability of the entire financial system, as has been seen with the recent crisis in the United States. This is particularly important in the context of the business sector. First of all, enterprises cover the majority of general loans, as opposed to consumer loans for the household sector. Secondly, at a time of constant threat of economic slowdown, and in a post-crisis period, it is worth paying attention to the sector in which the losses will be greater, and that is undoubtedly the enterprise sector.

The International Monetary Fund (IMF) (2003) defines stress tests as a set of techniques used to measure the sensitivity of an entity's financial portfolio to likely extreme events (Jones et al. 2004). Banks often have to explain the impact of an economic shock on risk parameters via the Basel II credit-risk framework (Basel Committee on Banking Supervision 2006, 2009). Under that, IRB banks must reflect an economic downturn in their risk parameters under Pillar 1 (Art. 177 CRR), or in line with the CEBS stress-testing guidelines (CEBS 2010), which require banks to consider a severe economic downturn in their calculations of internal-risk coverage under Pillar 2.

Stress tests are used at every level of risk management at a bank, including through the Internal Capital Adequacy Assessment Process (ICAAP); as well as in the construction of capital plans. The exact objectives of sensitivity analysis are not clear to all units tested, but depend on the structure of the body. However, the general idea is similar and was defined by the Office of the Polish Financial Supervision Authority $(2009 ; 2013 a, b)$ as ensuring the financial balance of a plan in the event of adverse development scenarios. The running of tests should improve an entity's corporate management, and be treated as one of the main risk-management tools.

It is worth noting that there is currently an interesting problem in Poland when it comes to tests of the banking sector. The process involved operates in such a way that each commercial bank individually defines the macroeconomic scenario, with the variables transferred to the PFSA differing fundamentally between them. If the assumptions and method of calculating parameters differ greatly, results are non-comparable from the very outset.

It was expected that the current pandemic would cause capital ratios to fall significantly further than the results of stress tests would suggest in the case of major shocks. Data on the latter are not available publicly, and it would definitely be worth considering suggestions for a central body, e.g. the PFSA, to start preparing macroeconomic scenarios. 
The main purpose of this article is to detail and offer a stress-testing framework that investigates the impact of COVID-19 scenarios on the probability of default of non-financial companies (the new micro stress-test). The work has addressed both the uniform and the asymmetrical transmission of shocks, and considers these in relation with company size and sector of activity. The two scenarios considered are a baseline one for a hypothetical state that would have been observed without COVID-19, as well as an adverse scenario that takes the impact of the pandemic into account.

To generate the stress tests, a general model was constructed using a two-step approach comprising microeconomic and macroeconomic modules. The former includes an internal rating system to estimate the probability of default (ICAS), while the macroeconomic module strives to capture the feedback effects from the macroeconomic stance into the banking sector, via the corporate-sector channel. Non-financial enterprises in Poland were assessed using data on banks' large exposures to non-financial enterprises, financial statements, data from the National Court Register and balance-of-payment figures for the external statistics of enterprises.

The proposed tool can be used in: (1) corporate risk assessment at sectoral and aggregate-economy levels; (2) the measurement of trends when it comes to the default rate in the corporate sector, with highlighting of the most reliable direction in which the NPL ratio is likely to move; (3) complementing the macro-prudential approach with a microeconomic perspective that calculates the portfolio put at risk by entities capable of exerting pressure on financial stability.

The present study extends these approaches by:

(1) filling a gap in existing research, given that there has been a strong focus on the risk of bankruptcy of large international companies and the dominance of stress scenarios subject to regulatory criteria (among banks, insurers and other financial-market entities), and also given the way in which non-financial entities build rating classes, and expose the risk of loss of liquidity, which is different from the approach associated with values for prudential indicators being exceeded,

(2) addressing the circumstance in which the crisis caused by the proliferation of COVID-19 represents the first of a pandemic nature in recent history, leaving the process of forecasting especially difficult,

(3) proposing scenarios for stress tests related to the impact of COVID-19,

(4) studying a unique and comprehensive Prudential Reporting database detailing significant exposures of whole commercial banks to the corporate sector,

(5) using a microeconomic module, i.e. a model for the probability of default in the corporate sector, to quantify developments a year ahead, when it comes to the quality of banks' corporate loans,

(6) using a macroeconomic (satellite) model, which assesses the relationship between macroeconomic variables and the risk parameter (the probability of default). 
An original contribution has been made in these matters and one that serves to expand upon existing research. Additionally, the proposed methodology can be used by banks and supervisory institutions, so it has major potential for use.

The remainder of this paper is organized as follows. Section 2 presents the literature review, and Sect. 3 the methodology; while Sect. 4 covers data sources. Section 5 presents and discusses the empirical results, and Sect. 6 concludes the paper.

\section{Literature review}

While studying the literature on the subject, previous researchers paid attention to the formation of a stress-test model of credit risk by reference to a macroeconomic model (i.e. Virolainen 2004; End et al. 2006; Jimenez and Mencia 2007; Schmieder et al. 2011; Chan-Lau et al. 2017). The first was Wilson (1997a, b), who introduced the macro stress testing method taken up by many scientists. Virolainen (2004) estimated a credit-risk model with macroeconomic variables for the enterprise sector. In addition, the author modelled the default rate by industry, providing for moreaccurate estimates of financial losses, as conditioned by the current macroeconomic situation. Stochastic simulations used by End et al. (2006) in turn allowed for the generation of loss distributions with extreme values, and for account to be taken of time variability and interactions between macroeconomic variables under extreme conditions. It became possible to take into account correlation variations between risk parameters-important, given the abundance in extreme scenarios. To accurately estimate the aggregate losses, Jimenez and Mencia (2007) included unobservable risk factors in a model that can be used to present contagion effects between sectors. And for their part, Chan-Lau et al. (2017) used bottom-up default analysis, with the prediction in this case relating to the probability of default for individual conditional companies in a given current macroeconomic and financial situation.

An alternative approach used and developed by researchers (e.g. Jakubik and Schmider 2008; Bandt et al. 2013) is one that follows Merton (1974). This method makes possible a transformation of macroeconomic changes into the probability of default. In connection with the New Capital Agreement, Jakubik and Schmider (2008) applied an extension of Merton's one-factor model to calculate capital requirements. It was concluded that the impact of economic shocks is more noticeable in countries at lower levels of development. The authors then suggested that global research be carried out, as it was felt that the application of a sufficiently advanced procedure for stress tests might actually protect against financial crisis. Heppe (2014) found that, in countries of more-limited financial stability such as Spain or Italy, the impact of adverse macroeconomic changes on the likelihood of bankruptcy is much more severe than it is in Germany or the United Kingdom. The author advocates uniform European stress-testing models.

Having studied the literature, we can conclude that micro stress-test analysis on a sample of companies has almost never been carried out. Altman (2010) explored this approach by stress-testing the parameters of the Z-MetricsTM model used to assess corporate credit risk. The first shock scenario was a $25 \%$ drop in company share prices, while the second assumed a 5\% decrease in the indicator measuring 
the company's profits in relation to its total assets. A third scenario then envisaged the two aforementioned shocks occurring simultaneously. The results showed, first, that the second shock scenario is more severe than the first. Second, the ratings of companies in the lower rating classes are subject to less variation. Scientists further advocate expanding the model from Altman (2010) to include small and large enterprises from around the world.

This chapter has reviewed the empirical literature containing the methodology used in stress tests. An important element of the economic market analysis is the forecasting of hypothetical impacts and sudden fluctuations in the business cycle. The experience acquired during the credit-market crisis shows that it is worth conducting this type of research. As banks do not have specific requirements as regards the running of stress tests, scientists propose many new solutions that improve their quality and simplify the methodology. This article attempts to introduce proposals for a new micro stress test into the subject literature. The focus of the paper is on an empirical analysis of the effects of adverse macroeconomic shocks on the corporate sector in Poland. To pin down the driving forces of firms' defaults, aggregate macroeconomic data are combined with microdata (firm-specific information).

By looking at the effects of COVID-19-the first pandemic crisis in recent history-the paper addresses what is obviously an important and extremely urgent topic. It is worth mentioning that the proposed methodology allows for capturing of the nonlinearity in the relationships between defaults and macroeconomic variables, which is especially relevant in times of crisis. Furthermore, the paper provides an assessment of credit risk of companies in Poland - an important player in the European and the global economy-which is per-se of interest.

\section{Methodology}

In order for stress tests to be performed, a general model was constructed using a two-step approach:

- The microeconomic module models the probability of default in the corporate sector, quantifying developments 1 year ahead as regards the quality of banks' corporate loans. The statistical model in question (Nehrebecka 2016) has parts that are quantitative - relating to financial factors $(F)$, and based on one component that considers historical data retrieved from Prudential Reporting (firm financial flexibility and the occurrence of delinquencies within a firm-bank credit relationship (credit history)), and one that uses financial-statement data for the enterprises concerned (encompassing profitability, financing structure, debt sustainability and asset types); as well as qualitative - concerning behavioral factors $(B)$ (location of the entity, industry, level of employment, legal form, year of establishment, description of the owner, payment morality).

The two parts of the model were combined in the formula:

$$
y=F^{\alpha} B^{\beta},
$$


where: $\alpha, \beta$ are coefficients $(\alpha \approx 0.7 ; \beta \approx 0.3)$.

The statistical model is built on a logistic regression approach, and produces an estimate of the annual probability of default (PD) of a company assessed. The model is estimated on categorized variables transformed using the weight of evidence (WoE) approach. The advantage of this is that no special treatment of missing and/or outlying data is necessary. Outliers are not cut off, while missing values simply form a category of their own.

The important element of the methodology is the link between PD at firm level and the macroeconomic variables. The calibration of this model based on approach presented by King and Zeng (2001) involves:

$$
\ln \left[\frac{P D}{1-P D}\right]=\alpha+X \beta+\ln \left[\frac{D R}{1-D R} / \frac{p}{1-p}\right],
$$

where: $P D$ is the calculated probability of default, $D R$ is the default rate at which the $P D$ is calibrated, $p$ is the average unadjusted computed probability of default for the forecast sample, $X$ is the explanatory variables vector.

- The macroeconomic module strives to capture the feedback effects from the macroeconomic stance into the banking sector, via the corporate-sector channel. The approach used for the macroeconomic module to achieve uniformity and apply to all firms is a one-factor Merton-type model with a latent factor applied to the Polish economy, which includes a default threshold dependent on the state thereof, in line with the methodology proposed by Jakubík (2007). The equation for the model is as follows:

$$
R_{i t}=\sqrt{\rho} F_{t}+\sqrt{1-\rho} U_{i t},
$$

where: $R_{i t}$ is the logarithmic asset return for each enterprise $i$ at time $t, F_{t}$ is the logarithmic asset return in the economy at time $t$, which is assumed to be a random variable with a standard normal distribution, $U_{i t}$ is the specific asset return to enterprise $i$ at time $t$, which is assumed to be random with a standard normal distribution, $\rho$ is the correlation between the asset return of two units with the systematic factor $F_{t}$.

This approach is based on Merton's model, according to which a firm defaults if the return on its assets falls below a latent default threshold that depends on the economic cycle. In empirical applications, the model imposes an assumption of homogeneous firms (Jakubík and Schmieder 2008). Homogeneity implies that asset returns of all firms follow the same process, and that the correlation of asset returns with the systematic factor $F_{t}$ is the same for all firms.

When applied to industries that differ with respect to their sensitivity to macroeconomic factors, the assumption of homogeneity is obviously violated. One way to address this issue is to estimate a different regression specification, e.g. allowing for industry-specific coefficients, or by estimating the regressions industry-wise (e.g. Yurdakul 2014) in order to explicitly capture the relationship between sectoral default rates and the macrovariables. 


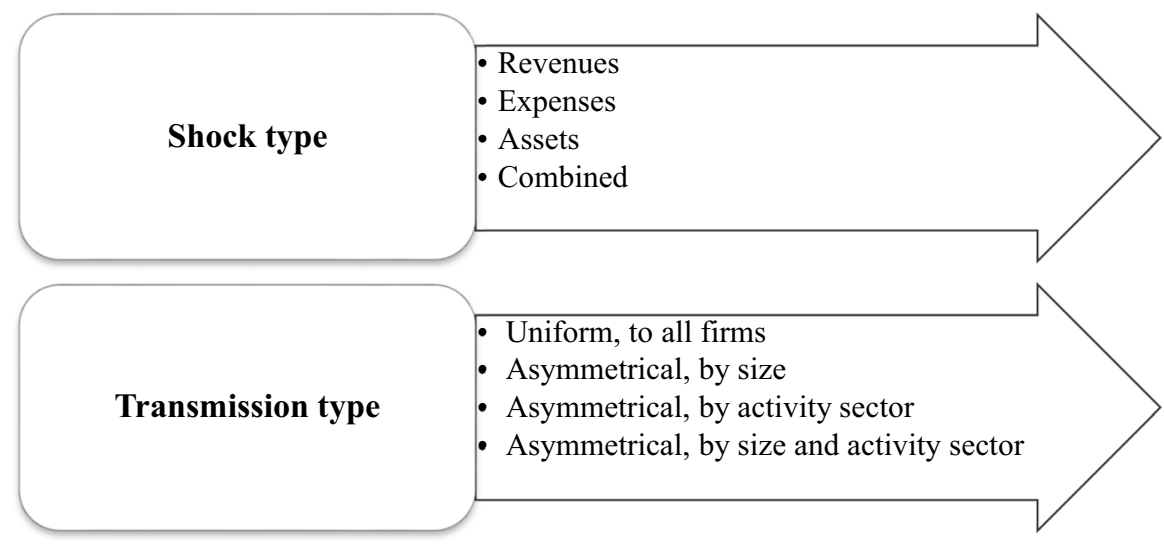

Fig. 1 Micro stress tests: Shock and transmission types Source: author's own elaboration

The macroeconomic module for asymmetrical circumstances, e.g. by sector of activity relies on the Arellano-Bond estimator-single-stage (Arellano and Bond 1991), with the default rate therefore relating to macroeconomic factors as follows.

$$
D R_{i t}=\rho D R_{i t-1}+\sum_{\mathrm{k}} \beta_{k} x_{k i t}+c_{i}+\varepsilon_{i t}
$$

where: $D R_{i t}$ is the default rate for each activity sector $i$ at time $t, \rho, \beta_{k}$ are unknown coefficients, $x_{k i t}$ is an explanatory variable, $c_{i}$ is the individual effect for activity sector $i, \varepsilon_{i t}$ is an error term.

A connection was established between the PD model and the macroeconomic module, with the aim being to capture the impact of macroeconomic developments.

\subsection{Theoretical description of the micro-prudential approach to stress tests}

The micro-prudential approach in stress-testing entails testing of the sensitivity of individual enterprises (or other target groups) to shocks defined previously. In this case, panel data on the financial statements of a company are used to estimate the value of the risk parameter (e.g. the probability of default) for that company under normal and stress conditions. The change in the risk parameter caused by macroeconomic shocks is determined by reference to changes in items to be reported for a given enterprise. Figure 1 depicts the stress tests.

Stress-test scenarios can be constructed on the basis of historical or hypothetical scenarios. Historical scenarios are built on the basis of significant past market disruptions. There are drawbacks to this type of approach to scenario-building. Firstly, stress-tests built on the basis of them fail to take new risks into account. Secondly, the duration of disturbances and their severity are often inadequate to the current conditions. Third, the level of risk and impact of systemic interactions may turn out to be underestimated - as was the case for information obtained during the financial 
Table 1 Example of scenarios in micro stress tests in force from 2009/2008 Source: author's own elaboration based on financial statement data (from AMADEUS, NOTORIA and BISNODE)

\begin{tabular}{lll}
\hline & $2009 / 2008$ & \\
\hline & Revenues (\%) & Expenses (\%) \\
Total firms & 0.2 & -0.2 \\
& By size & \\
Large & -5 & -5 \\
SMEs & 8 & 8 \\
& By activity sector & \\
Mining & -4 & 6 \\
Manufacturing & -2 & -3 \\
Utilities & 9 & 6 \\
Construction & -2 & -3 \\
Trade & -1 & -1 \\
Services & 6 & 6 \\
Real estate & 5 & 2 \\
\hline
\end{tabular}

crisis of 2009/2008 (see Table 1). The Covid-19 stress scenario seems much more severe than anything so far observed in the data. The estimation conducted on historical data therefore yields an invalid prediction of responses to a shock unprecedented in its nature and severity.

Banks may also implement stress-tests using hypothetical scenarios based on severe but possible future scenarios. However, the use of hypothetical scenarios is associated with the risk of only moderate scenarios being created (with too low a degree of severity and/or too low a level of interaction). This was the case before the crisis, it proving difficult to have risk managers create more-severe scenarios. Extreme scenarios were simply considered impossible.

Drawing on information from the news and other sources in regard to possible changes in macroeconomic variables (e.g. inflation, real GDP, etc.) several variants are possible, with-for example - a major shock being a change in real GDP by say $5 \%$, while average or small ones are of for example $2 \%$ and $1 \%$. Assuming the link between variables defined as of the shock type at firm level, as well as macroeconomic variables, a 5\% change in real GDP translates into a 10\% change in corporate revenues. In the above case there is endogenous shock (see Fig. 2). Such changes in companies' financial ratios are then placed in the PD model (the model is not changed, i.e. the parameter estimates remain unchanged, we only change the values of the translated variables depending on the scenario). The PD model does not contain macroeconomic variables directly, merely financial indicators of the group of enterprises serviced by the bank. Macroeconomic variables are not included in the model because we explain the impact of changes in the economic situation on the financial indicators of enterprises a step earlier, i.e. we would have a direct and indirect impact. The assumption made is therefore that changes in the economic situation affect the results of enterprises, as opposed to the other way around. Additionally, as a last resort, it is possible to consider the 

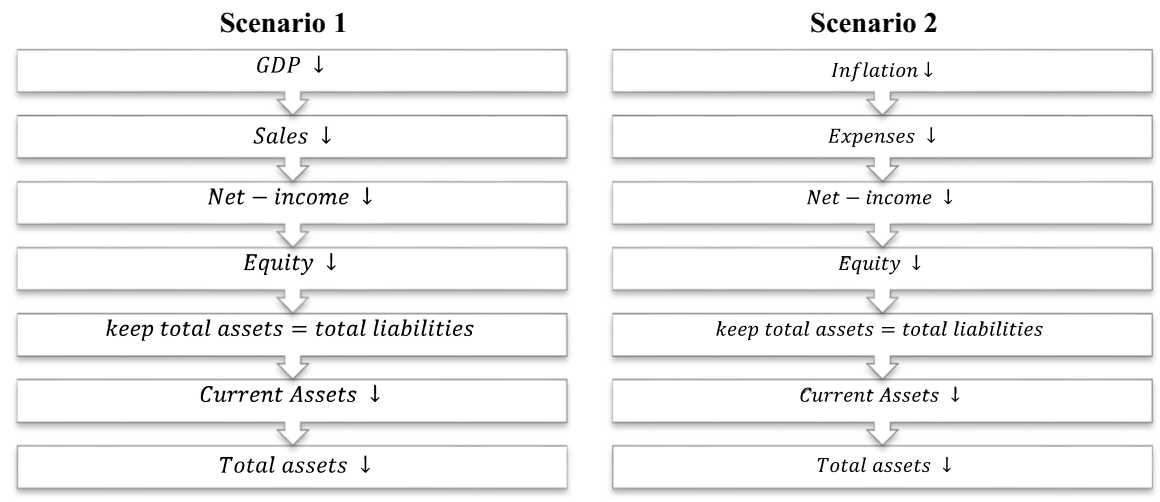

Fig. 2 Micro stress tests: Scenario calibration and transmission Source: author's own elaboration

following whereby both financial and macroeconomic variables are present, but then in the test scenarios we only change the values of macroeconomic variables and leave the financial indicators unchanged in line with an assumption that they will change in the next year (in line with lagged impact).

This article uses scenarios defined on the basis of exogenous shocks (i.e. based on information obtained from the March 2020 financial statements of such major players on the market as PGE, Tauron, Enea, Energa, PKP Cargo, Agora, Boryszew, LPP, KGHM, Erbud, JSW, PKP Cargo, VRG, Sanok, etc.).

In the running of stress tests, channels will be presented that may affect Poland's economic situation in connection with problems relating to COVID-19. The first channel on which the Polish economy may suffer is foreign trade. The first COVID19 infections appeared in China. Poland is in second place on the list of main importers (based on OECD data). Production chains in Poland may be affected by the above supply shock. Many Polish companies import intermediate goods from China with a view to their being involved in further production. In the computer and electronics industry, the share of imports accounted for by China is as high as $40 \%$. The textile and clothing industry is in second place, with a share of $37 \%$; followed by non-metallic raw materials (20\%); as well as machinery and equipment (14\%). The channel involving export to China does not pose a major threat to Poland, with China in 20th place among main recipients of our exports (representing just $1 \%$ of the total). Equally, it is worth noting that the transport sector (airlines and freight transport) has been the first to feel the effects.

A second channel via which the Polish economy may suffer is associated with subsequent COVID-19 outbreaks within the Eurozone. Our main trading partner in this context is the German economy. It is worth mentioning the automotive sector, which faced challenges with new exhaust-emissions standards even before the problems relating to COVID-19 arose, with new and expensive investments necessitated, and the result being an increase in net debt as the sector's margin fell. Poland is a supplier of auto parts, and thus plays a significant role in production chains. At the time of writing, the trend for new car sales in the EU has involved a 7\% drop. 
A third channel via which the Polish economy may suffer reflects the situation in Italy (whose economy is service-sector-dependent). This may contribute to a decrease in exports from Poland, as Italy is the 5th-largest recipient of these (with a key role involving the aforesaid automotive industry, which Poland supplies with parts). Equally, what Poland imports (to the tune of 5\% of the total in Italy's case) are machines, metals, non-metallic raw materials and intermediate goods (e.g. within the textile and clothing industry). As for the scale of the impact of the phenomenon associated with COVID-19, the supply shock from Italy is much weaker than that from China.

It is also worth mentioning the tourism industry, which is also facing major challenges globally. However, in Poland, this sector generated less than 5\% of GDP as of 2018 , compared to a country like Croatia in which the figure is $25 \%$.

An important threat channel for our economy relates to the fact that restrictions were introduced on the opening of stores, while the public is less willing to make purchases. A major question mark is whether traditional trade will move to e-commerce and will be able to meet possibly increased demand. The example of China and Western Europe shows that a prolonged period of trade restriction can see reduced willingness to buy on the part of households. Uncertainty is also present on the financial markets, with the economy facing further danger as every industry is affected. A threat to retail trade translates into further problems and difficulties in transport, and in the textile and clothing, construction, chemical and automotive sectors.

On the other hand, the SME sector (not to mention microenterprises currently suspending operations) will experience a significant impact due to COVID-19, as well as difficulties in surviving on the market. An increase in numbers of bankruptcies and restructuring are to be anticipated at the end of the year. Currently, payment gridlocks in the food-distribution channel are increasing (many companies are freezing funds). The liquidity situation is deteriorating. Does reducing credit costs for SMEs help with survival on the market? Probably not. And will defense against recession be possible on the basis of other activities, such as the anti-crisis shieldthe second factor-fiscal stimulation-to a considerable value of PLN 220 billion, or $8 \%$ of annual GDP (covering ZUS social-insurance payments, special loan and credit systems, healthcare, and a public investment program)?

In summary, most companies are experiencing or will experience effects of the pandemic. However, there are sections that will be hit especially hard, as they involve services that, due to the ban on gatherings and the recommendation to avoid crowds, will lose most of their revenue and fail to make up for this loss in the future.

It was on the basis of considerations such as the above that scenarios were formulated in micro stress tests in force in the March-June 2020 period (as presented in Table 2). These scenarios are difficult to compare to past crises and/or to historical distributions of the respective variables-as the Covid-19 stress scenario seems much more severe than anything so far observed in the data. 

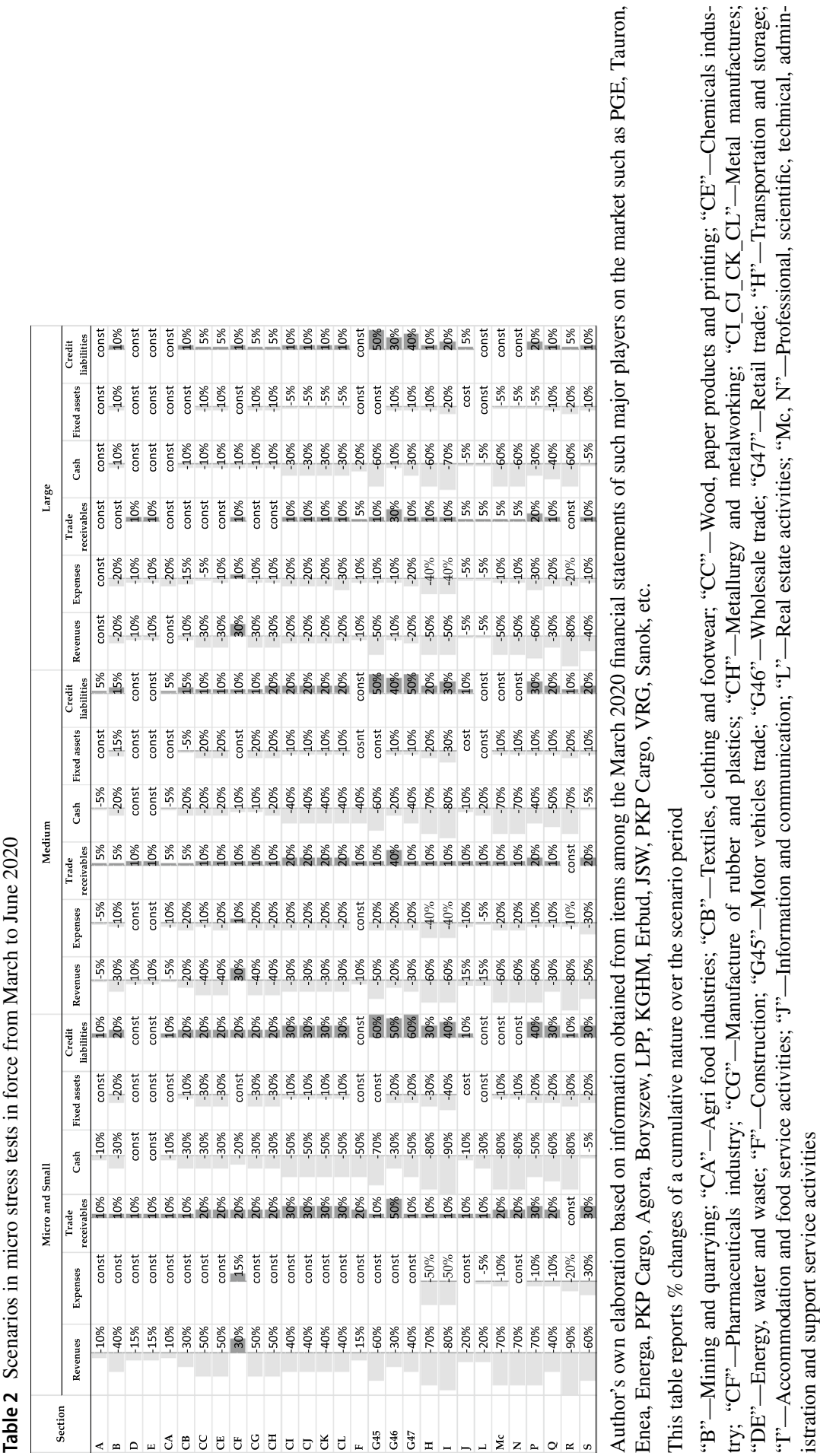


\section{Data sources}

\subsection{Data sources for the microeconomic module}

The empirical analysis was based on individual data for the years 2007-2020 of the following kinds:

- data on bank borrowers' defaults, drawn from the Prudential Reporting managed by the National Bank of Poland, NBP (reflecting Resolution of the Board of Narodowy Bank Polski No. 53/2011 of 22 September 2011, which related to procedure and detailed principles whereby banks would supply the NBP with data indispensable to its pursuit and periodic evaluation of monetary policy, as well as evaluation of the financial situation facing banks, and banking-sector risk), with the so-called large exposures regarded by banks as joint-stock companies, state-run banks and non-associated cooperative banks as in excess of 2 M PLN in the case of a single enterprise;

- data on insolvencies from the database managed by the National Court Register (Krajowy Rejestr Sadowy), i.e. the Polish Business Register (or register of economic activity);

- financial statement data (from AMADEUS, NOTORIA and BISNODE);

- data on the external statistics of enterprises (from the NBP).

For the purposes of further work, sectors excluded from the Polish Classification of Economic Activity 2007 sample were those in Sections A (Agriculture, forestry and fishing) and K (Financial and insurance activities). This was a reflection of the specific nature of these activities and the separate regulations applying to them. The legal forms analyzed were in turn partnerships (unlimited, professional, limited or joint-stock limited); capital companies (limited liability or joint stock); civillaw partnerships, state-owned enterprises and Poland-based branches of foreign enterprises.

Probability of default (PD) is one of the key parameters to be estimated in creditrisk modeling, and is especially important to the design of classes of risk and the comparison of different rating scales. However, too little attention would seem to be paid to various possible definitions of default in practice, even though a clear understanding is key to proper interpretation of assessed PD. The two definitions presented here are deemed "narrow" (relating to failure, and based on an entity under consideration filing a formal application for bankruptcy proceedings), or else "broad" (relating to default as per the definition in Regulation (EU) No. 575/2013 of the European Parliament and of the Council of 26 June 2013 on prudential requirements for credit institutions and investment firms and amending Regulation (EU) No 648/2012 (\$178 CRR $\left.{ }^{1}\right)$.

\footnotetext{
1 "Article 178.

Default of an obligor.

1. A default shall be considered to have occurred with regard to a particular obligor when either or both of the following have taken place:

(a) the institution considers that the obligor is unlikely to pay its credit obligations to the institution, the
} 

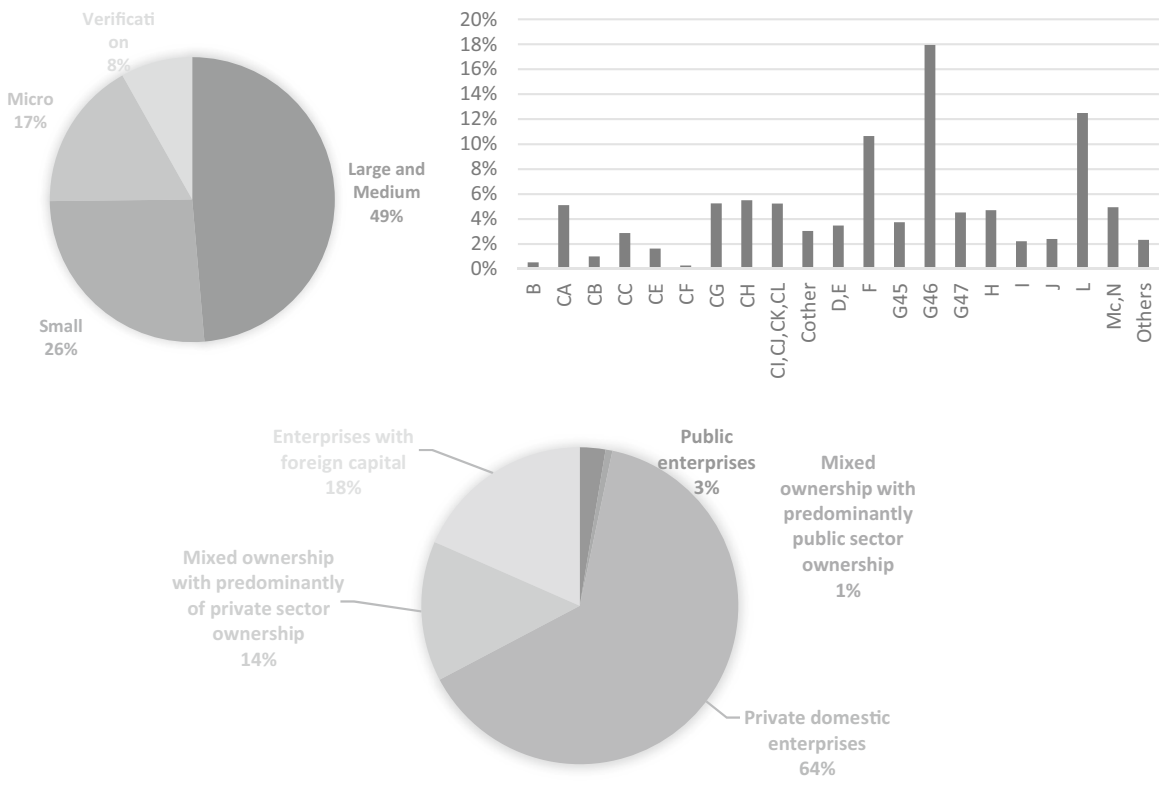

Fig. 3 Structure of the analyzed sample by size, ownership structure and section/subsection for nonfinancial-enterprise operations conducted-2019

Source: author's own elaboration based on the Prudential Reporting managed by the National Bank of Poland

Definition of the total number of obligors depended on use of selection criteria as follows:

(1) Only companies were selected.

(2) Companies belong to the non-financial sector in line with the definition from the European Systems of Accounts, ESA (2010).

(3) Companies are established in Poland.

(4) Companies are in existence (operating and not liquidated or in liquidation) throughout the entire year concerned.

(5) Companies are not in default (in respect of either the insolvency criterion or other types of default under the CRR definition) at the beginning of the year.

Footnote 1 (continued)

parent undertaking or any of its subsidiaries in full, without recourse by the institution to actions such as realizing security;

(b) the obligor is past due payment by more than 90 days on any material credit obligation to the institution, the parent undertaking or any of its subsidiaries. Competent authorities may replace the 90 days with 180 days for exposures secured by residential or SME commercial real estate in the retail exposure class, as well as exposures to public sector entities). The 180 days shall not apply for the purposes of Article 127'. 
(6) Information on the (default-)state of the company is available throughout the year (uninterruptedly), meaning confinement to situations in which there are entries in the credit register for all 12 months.

(7) The total exposure reported in the credit register is at least $2 \mathrm{M}$ PLN for each reporting date.

The total number of obligors obtained was 15,735 enterprises as of January 2019, the loan commitments of which amount to PLN 328,941 M. Loans and other receivables of non-financial enterprises in Poland account for 371,696.3 M (based on NBP statistics-monetary receivables and liabilities of financial institutions/banks). It is worth noting that public enterprises accounted for $3 \%$ of the total, mixed ownership with predominantly public-sector ownership for $1 \%$. Such companies may prove less vulnerable to shocks where they are supported directly.

The structure of the analyzed sample by size, ownership structure and business section/subsection for activities of non-financial enterprises is as presented in Fig. 3. Among these, 375 enterprises had defaulted with at least one bank.

\subsection{Data sources for the macroeconomic module}

Data used in constructing the macroeconomic credit-risk module were selected from monthly macroeconomic time series (between January 2007 and December 2019). All the assumptions for the stress test derive from the NBP's macroeconomic forecasting model (NECMOD), with a view to consistency being assured between this instrument used for price-stability purposes, and the financial-stability tool presented here. The dependent variable is the registered quarterly default rate.

Figure 4 presents rates of insolvency and default in different years by reference to the analysis sample, which was prepared with criteria (1)-(7) on page 9 applied. During the crisis on global financial markets of 2007-2009, Poland's rate of GDP growth fell from 6.6 to $3.2 \%$, while numbers of declared bankruptcies in the economy increased by 54.6\%. It was in 2009 that the greatest increase in numbers of insolvency proceedings was noted. The default rate that year stood at $8 \%$, for total exposures exceeding 2 M PLN. In 2012, Polish courts declared 877 businesses bankrupt - the worst result at any time in the last 8 years, partially explicable in terms of the 2012 economic downturn (with GDP growth rate not then exceeding 3.3\%, and falling to $0.1 \%$ in the fourth quarter). A second local maximum (of $6 \%$ ) for default rate could be noted, while the figure for 2019 was around $2.4 \%$.

\section{Results}

\subsection{Results for the microeconomic credit-risk module}

The first stage (microeconomic module) is related to the construction of the probability of default (PD) model for the corporate sector. The framework was established 


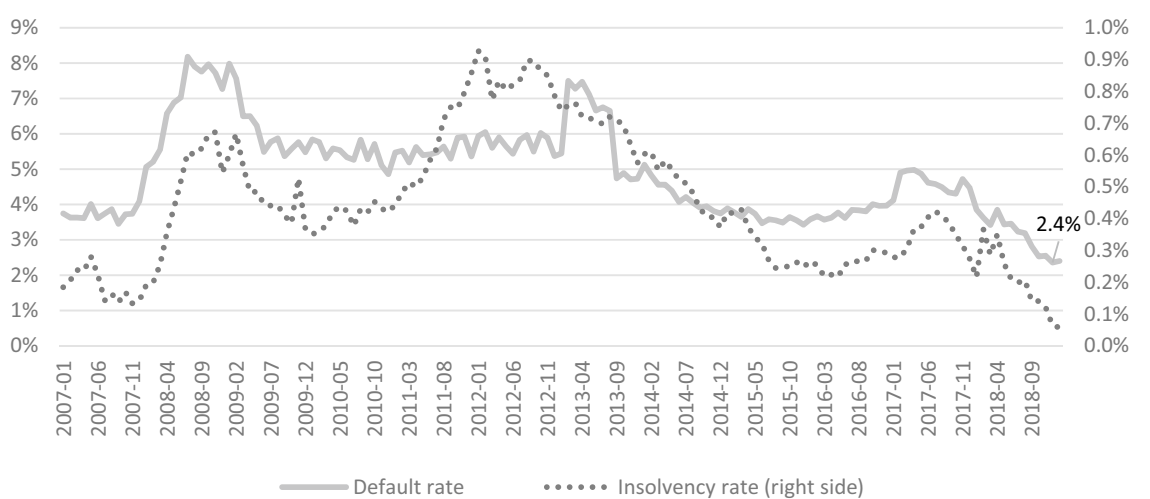

Fig. 4 Insolvency rates and default rates in the 2007-2019 period the Prudential Reporting managed by the National Bank of Poland

Source: authors own elaboration based on the Prudential Reporting managed by the National Bank of Poland and the National Court Register. Note: Insolvency rate is deemed "narrow" in relation to failure, and based on an entity under consideration filing a formal application for bankruptcy proceedings. Default rate is "broad" as per the definition laid down in Regulation (EU) No. 575/2013 of the European Parliament and of the Council of 26 June 2013 on prudential requirements for credit institutions and investment firms and amending Regulation (EU) No 648/2012 (\$178 CRR)

using micro data, with a bottom-up approach, and adoption of the Basel II definition of default. Experimentation here sought to outline the microeconomic factors best accounting for companies' behavior as they service their debts with banks.

The PD model for the corporate sector of the Polish economy (Table 3) was computed via the methodology from Nehrebecka (2016). Variables used and their individual performances are as detailed in the "Appendix" (Table 7). Empirical study shows that the main factors behind a firm's ability to service its bank debts in the quantitative aspect are from financial statement data: (1) ROS, (2) Equity-to-debt, (3) Profit before tax, (4) Financial Leverage = (interest-bearing borrowings, non-current + interest-bearing borrowings, current)/assets, total, (5) Current liquidity = cash and cash equivalents/liabilities, current, total. An increase in ROS is linked to a reduced probability of default. Higher financial leverage indicates that a company could have difficulties servicing its financial obligations vis-à-vis commercial clients and financial creditors. The indicator for profit before tax (weight of $8 \%$ ) is the group of second most important characteristics. Profit before tax has a significant impact on credit-risk assessment, indicating a firm's development of its activity. Companies for which this indicator does not exceed PLN 4,860,499 were considered most endangered. Where equity-to-debt is concerned, equity measures the stability of a company in the sense that, where it has taken on a non-profitable project or made a wrong business decision, it will only survive and stay on the market if it has the equity to absorb losses. Equity thus acts like a reserve or buffer when losses occur. A low amount of equity in the face of debt suggests a greater PD. A creditor is primarily interested in the ability of the trade-credit debtor to pay its current liabilities. However, not only the liquidity of the enterprise is important, but also the long-term prospects, i.e. whether payment of all liabilities is going to prove possible. 


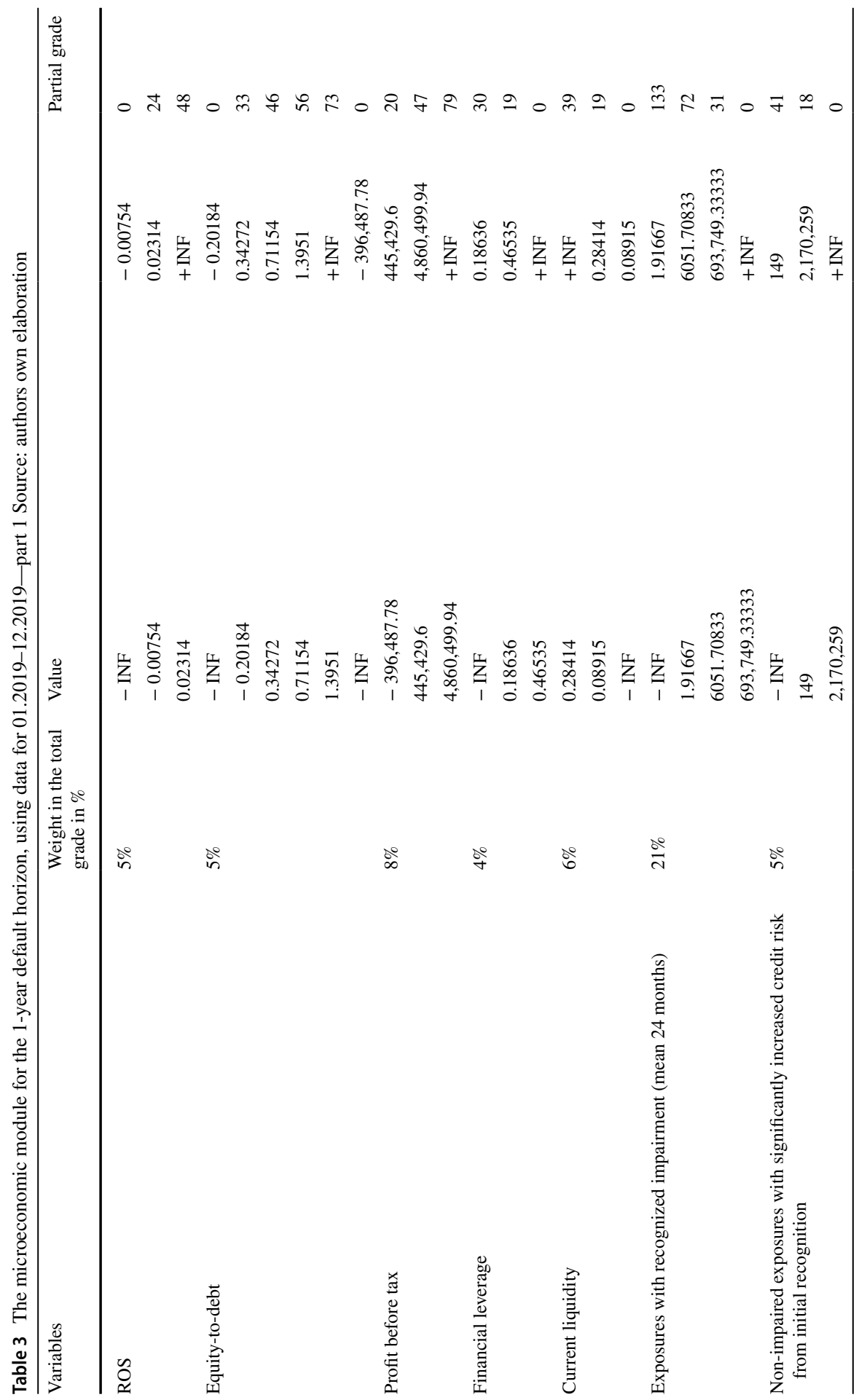




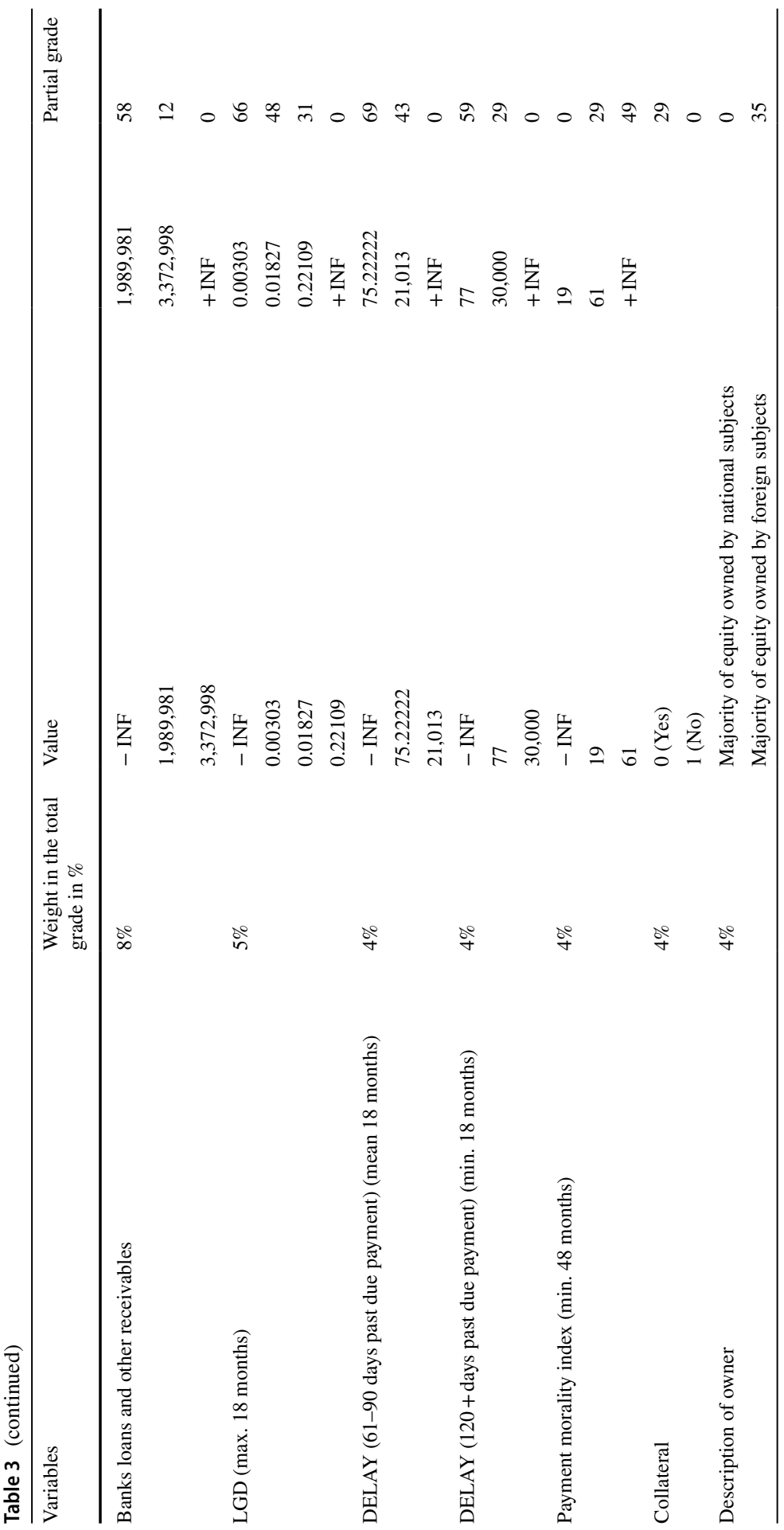




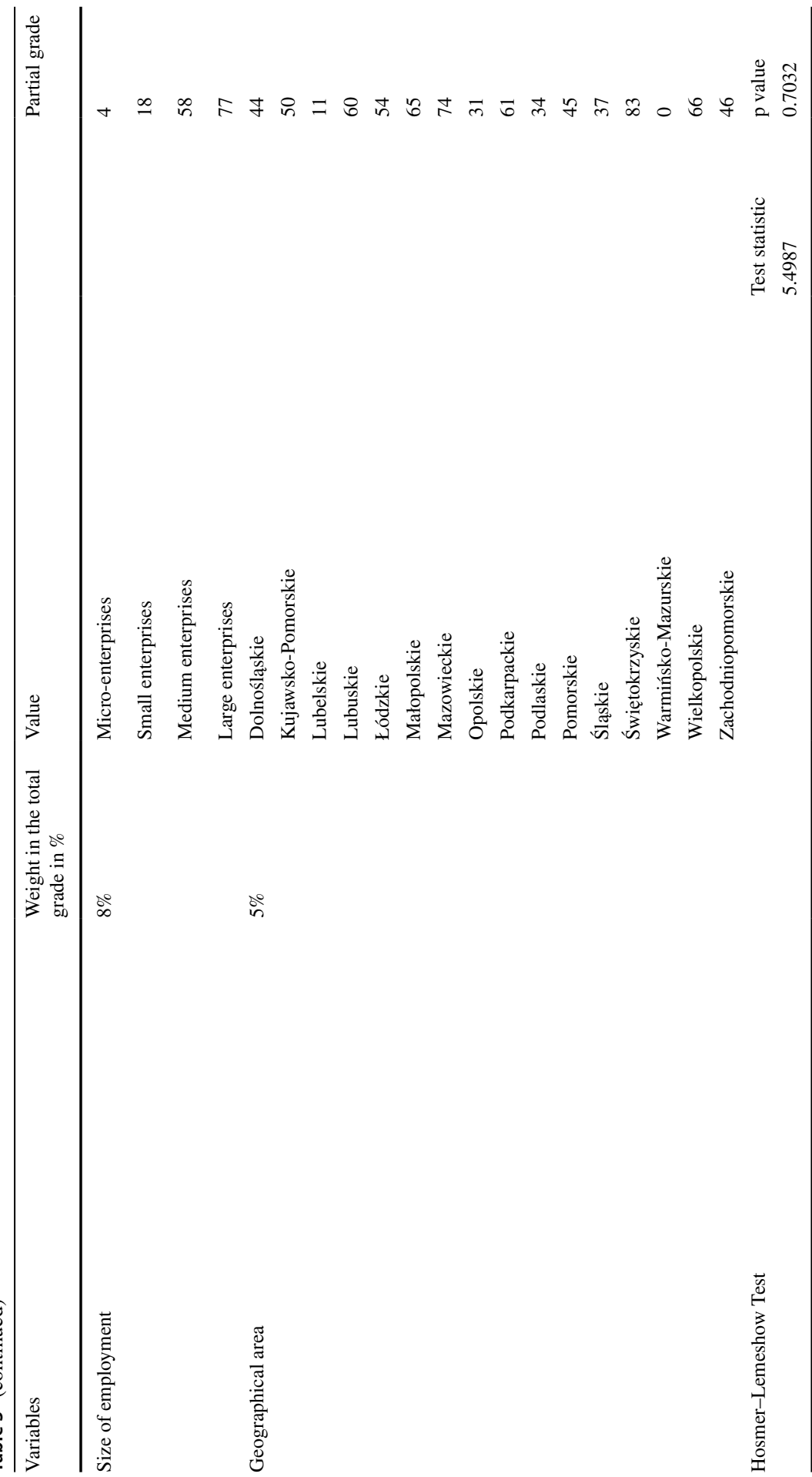


Solvency ratios are important to a creditor for these reasons. On the other hand, if an enterprise fails to yield enough profit, it will face the problem of repayment of debts in the future. The profitability ratios of the debtor also become important to the creditor in this way.

The main factors behind a firm's ability to service its bank debts are encapsulated by Prudential Reporting on: (1) banks loans and other receivables, (2) exposures with recognized impairment, (3) non-impaired exposures with a significant increase in credit risk from initial recognition, (4) collateral, and (5) LGD. A borrower's relationship with the bank and repayment of bank loans or in general, and indeed all the history of a company with a bank, can provide for better assessment of risk given the long-term familiarity. Delays in repayments of other bank loans can be seen in the interbank system, representing another good signal regarding a company's operations and its repayment discipline. The greatest weight was assigned to the indicator of exposures with recognized impairment (37\%). The best grade was awarded to companies for which this ratio does not exceed PLN 6052, while the highest risk of default was taken to characterize companies whose indicators are below PLN 693,749. Collateral is the security a bank enjoys if a company defaults. Exposure risk attendant upon a loan is low where the market value of collateral at the time of default is high. The presence of security has a marked effect on LGD. Where default occurs, there is always a risk relating to the proper finalization of security, and this should be taken account of as the level of protection is being assessed.

The main factors behind a firm's ability to service its bank debts in terms of the qualitative aspect are: (1) the payment morality index, (2) overdue payments and (3) the size of the enterprise as measured by the number of employees (a weighting of $8 \%$ is assigned to the group of second most important characteristics), as well as (4) geographical area, and (5) the description of the owner. The payment morality index illustrates the payment morality of the examined entity in relation to selected suppliers who participate in the Bisnode (International Payment Monitor) payment monitoring program. Reference to this allows for assessment of the (average) degree of payment delay, which in turn helps with evaluating an entity's future payment behavior. In the case of companies publishing financial data, the value of payments registered in the program is scaled to turnover, with account also taken of the average rotation of the company's short-term liabilities. The payment morality index is presented on a scale of $0-80$ (being set to 0 if a company's average payment delay over 120 days past due payment). The period of time over which account receivables are converted into cash has direct implications for default: a delay of cash-inflows from customers will ultimately translate into a delay in debt service payment capable of causing a firm to default. Delayed payments represent information from suppliers as to reliability in the paying of invoices, also on the basis of an exchange of receivables and bailiff auctions.

To assess robustness, the model was then implemented in respect of a holdout sample and out-of-time sample to check for variables' predictive power. In the case of the holdout sample, the Gini coefficient assumed a value of 0.8251; while for the out-of-time sample the comparable figure was 0.824. The Kolmogorov-Smirnov statistic was computed, with the value of 66 obtained confirming the model's excellence. 
The individual probability of default (PD) is calibrated using the annual default rate (percentage of companies newly-defaulted in the last 12 months). To obtain a more accurate calibration function, the logarithm of odds is not replaced by an approximation (the $\log$ of probability of default). The theoretical relationship between the score and the logarithm of odds (which the regression suggests should be linear) was therefore used, with the accuracy of estimated PDs for each function tested using the Population Stability Index (whereby values between 0 and 0.1 denote no significant changes).

As model calibration is being validated, it is worth testing its power in relation to both individual classes and entire internal ratings. The first group of tests-only applicable to a single rating grade over a single time period-comprises the binomial Clopper and Pearson, Agresti and Coulla, and Wald Tests; the corrected binomial Wald test; the Wilson binomial and corrected binomial Tests and the one-factor-model (Emmer and Tasche 2005). As an important aspect here is the correlation of the default phenomenon between individuals (De Servigny and Renault 2002), three additional tests were used applying the moment-matching and granularityadjustment approaches (Tasche 2003).

The second group of tests offering more advanced methods of testing for adequacy of the default probability prediction over a single time period for several rating grades comprises the Spiegelhalter, Hosmer-Lemeshow and Blöchlinger Tests.

While accuracy of prediction is certainly a beneficial feature, a model can be even more useful when it goes beyond the mere prediction of past outcomes, and even beyond the forecast for an average firm, but when it allows the conditional distribution of default probability to be simulated. This may for example be achieved by adding a stochastic term to the predicted probability of default (in the case of the logistic regression this would be a logistically-distributed random variable with 0 mean). It is then possible to simulate firms' individual outcomes (individual PD), and even say something about the variation of projected PDs within each industry. Results are presented in Table 4.

Model was estimated on variables transformed into WoE which were then standardized. The stepwise method was used. A model for alpha equal to 0.05 was estimated for the modeling sample. Details on performance and the categorization of variables chosen in this way for the scoring card can be found in the "Appendix" and in Table 7.

As can be observed, variables' powers are satisfactory (see Table 4). Moreover, parameter estimates confirm the expected relation between WoE and probability of default, all parameters being significantly negative.

\subsection{Results from the macroeconomic credit-risk module}

The second stage concerns the bridging of the PD corporate model with the macroeconomic module, with a view to achieving capture of the feedback effects macroeconomic stance has on the banking sector. The module provides for an evaluation of the capacity of companies in a bank's portfolio to withstand normal or stressed macroeconomic scenarios. 
Table 4 The microeconomic module for a 1-year default horizon, using data for 01.2019-12.2019—part II Source: author's own elaboration

\begin{tabular}{lrlrl}
\hline Variables & Coefficient & Standard error & Wald Chi sq & $\mathrm{p}$ value \\
\hline The quantitative part & & & & \\
Constant & -1.470 & 0.091 & 259.699 & 0.000 \\
ROS & -0.620 & 0.112 & 30.801 & 0.000 \\
Equity-to-debt & -0.351 & 0.118 & 8.792 & 0.003 \\
Profit before tax & -0.451 & 0.182 & 6.110 & 0.013 \\
Financial leverage & -0.646 & 0.175 & 13.675 & 0.000 \\
Current liquidity & -0.385 & 0.179 & 4.641 & 0.031 \\
Exposures with recognized impairment (mean & -0.555 & 0.108 & 26.450 & 0.000 \\
$\quad$ 24 months) & & & & \\
Non-impaired exposures with significantly & -0.555 & 0.168 & 10.962 & 0.001 \\
$\quad$ increased credit risk from initial recognition & & & & \\
Banks loans and other receivables & -0.602 & 0.098 & 37.751 & 0.000 \\
LGD (max. 18 months) & -0.353 & 0.092 & 14.834 & 0.000 \\
The qualitative part & & & & \\
Payment morality index (min. 48 months) & -0.347 & 0.157 & 4.894 & 0.027 \\
DELAY (61-90 days past due payment) (mean & -0.733 & 0.267 & 7.524 & 0.006 \\
$\quad$ 18 months) & & & & \\
DELAY (120+days past due payment) (min. & -1.750 & 0.517 & 11.459 & 0.001 \\
$\quad$ 18 months) & & & & \\
Collateral & -1.144 & 0.337 & 11.536 & 0.001 \\
Description of owner & -0.780 & 0.329 & 5.609 & 0.018 \\
Size of employment & -0.745 & 0.172 & 18.753 & 0.000 \\
Geographical area & -0.906 & 0.252 & 12.945 & 0.000 \\
\hline
\end{tabular}

The approach entailing uniformity, to all firms used is a Merton model with a random latent factor, which includes a default threshold dependent on the state of the economy. The model was estimated by maximization of a likelihood function, and a standard normal distribution was assumed. The annual default rate across the non-financial corporations sector was in line with the macroeconomic baseline scenario. Variables proving statistically significant in explaining the corporate default rate are: (1) annual GDP growth; (2) annual inflation rate; and (3) nominal interest rate. Values for the error were tested for both autocorrelation and heteroskedasticity. The model specification that includes these variables is characterized by the smallest root-mean-square error (RMSE).

The equation was reformulated in the following form:

$$
D R_{t}=\Phi\left(\beta_{0}+\beta_{1} G D P_{t-1}+\beta_{2} \text { Nominal Interest Rate } \text { t-2 }+\beta_{3} C P I_{t-4}\right),
$$

where: $D R_{t}$ is the default rate for the corporate sector, $\beta_{0}$ is a constant term, $X_{t}$ is the vector of macroeconomic variables, $\beta_{1}, \ldots, \beta_{3}$ are values for the coefficient vector. 
Table 5 The macroeconomic credit-risk module entailing uniformity, to all firms Source: author's own elaboration

\begin{tabular}{lll}
\hline Variables & Lag & Coefficient (standard error) \\
\hline Constant & & $-1.8232(0.0096)$ \\
GDP growth (year-on-year) & 1 & $-0.0227(0.0018)$ \\
Nominal interest rate & 2 & $0.0751(0.0028)$ \\
CPI (year-on-year) & 4 & $-0.0152(0.0025)$ \\
Effect of latent factor $\rho$ & & $0.0078(0.0500)$ \\
R-squared & & 82.67 \\
LR-test & 93.76 \\
RMSE & 0.00043 \\
\hline
\end{tabular}

In line with Eq. (5), lagged macroeconomic variables are in line with the fact that a company must be at least 90 days past due payments to be considered in default. The results of this estimation is presented in Table 5.

Results show the default rate in the economy related negatively to gross domestic product. Real GDP growth translates into an increase in corporate income and a decrease in the probability of bankruptcy. By contrast, the level of credit risk correlates directly with interest rates. The short-term interest rate is widely used by banks as a benchmark to determine the rate at which banks grant loans at a variable interest rate. This rate is also used to estimate the interest rate on the securities market at which enterprises sell debt securities to finance their activities. Therefore, the increase in the interest rate will increase the probability of enterprises going bankrupt by increasing interest costs. Inclusion of inflation in the model reduces the effect of nominal interest rates lagged by four quarters, by real inflation lagged by two quarters. For this reason, the estimate of the coefficient representing inflation in the model achieves a negative result. High inflation translates into higher costs for enterprises, and thus contributes to the reduction of loan-repayment possibilities. However, higher inflation also denotes lower real debt.

It is worth noting how simple linear regression was practiced in regard to the banking sector, in order to model the impact of macro variables on PD. Where corporate contracts are concerned, the use of linear regression will never allow the desired quality of the forecast as in this article to be achieved. Based on the experience of regulators, the relationship described by the Merton model with a latent factor works well for corporate contracts, even as it fails to operate in the circumstances of retail contracts.

The macroeconomic module entailing asymmetry, e.g. by sector of activity relies on the one-step Arellano-Bond estimator (Arellano and Bond 1991), relating the default rate to macroeconomic factors. Its set of explanatory variables includes a lagged dependent variable, with individual entities potentially being characterized by significant heterogeneity, and with some regressors potentially endogenous. Moreover, the correlation between the individual effect of entities and the lagged dependent variable introduced for modeling results in the non-compliance of standard estimators used for static models (OLS estimator for panel data, fixed-effects estimator and random-effects estimator). Free from this drawback are the estimators 
Table 6 The macroeconomic credit-risk module in circumstances of asymmetry, e.g. by sector of activity

\begin{tabular}{llll}
\hline Variables & Lag & \multicolumn{2}{l}{$\begin{array}{l}\text { The one-step estimator of Arellano-Bond first } \\
\text { differences }\end{array}$} \\
\cline { 3 - 4 } & & Coeff & [std. err.; p value] \\
\hline $\begin{array}{l}\text { The explained variable lagged by one } \\
\text { period }\end{array}$ & 1 & $0.6736^{* * *}$ & {$[0.0219 ; 0.000]$} \\
$\begin{array}{l}\text { GDP growth (year-on-year) } \\
\text { Nominal interest rate }\end{array}$ & 0 & $-0.0980^{* * *}$ & {$[0.0059 ; 0.001]$} \\
$\begin{array}{l}\text { CPI (year-on-year) } \\
\text { REER (quarter-on-quarter) }\end{array}$ & 2 & $0.3568^{* *}$ & {$[0.0445 ; 0.000]$} \\
\hline & 2 & $-0.0838^{* * *}$ & {$[0.037 ; 0.026]$} \\
\hline $\begin{array}{l}\text { Arellano-Bond test } \\
\text { Sargan test }\end{array}$ & 1 & $0.0267^{* *}$ & {$[0.006 ; 0.000]$} \\
\hline
\end{tabular}

The following instruments were used for the equation on the increments: default rate ${ }_{\mathrm{t}-2}, \Delta \mathrm{GDP}$ growth, $\Delta$ Nominal Interest Rate, $\Delta$ CPI, $\Delta$ REER. The symbols $* * * * * *$, denote the statistical significance of parameters at the significance levels of $1 \%, 5 \%$ and $10 \%$, respectively. Arellano-Bond test-a test for the presence of second-order correlations in the first differences of the random component. Sargan test-a test for the correctness of instruments in the equation on increments, in the sense of their non-correlation with the random component of the model

dedicated to typically dynamic panel models. Among them, the most suitable is the one-step Arellano-Bond estimator-as based on the generalized moment method (GMM). The problem of correlation of the random component with endogenous variables is solved where account is taken of so-called instruments (variables strongly correlated with the explanatory variables, but independent of random error). In the case of the one-step Arellano-Bond estimator, lagged instruments are used in the equation for increments. A more detailed description can be found in, for example, Arellano (2004), Baltagi (2005) and Mátyás and Sevestre (2008).

The models were diagnosed in terms of the correctness of the selection of instruments using the Sargan test, verifying the non-correlation of the instruments with the purely random component of the model, for the equation on increments and levels, respectively. Additionally, the Arellano-Bond test was used to verify the postulate of no second-order correlation in the first differences of purely random error. In essence, therefore, it was the consistency of the estimators obtained that was checked.

The results of the estimation performed on the entire available dataset are as presented in Table 6. No objections were raised to the estimated model from the econometric point of view. With none of the models does the Arellano-Bond test offer grounds to reject a null hypothesis regarding the lack of second-order correlation in the first differences of purely random error. Moreover, there are no grounds for rejecting a further null hypothesis as to the correctness of the instruments used in terms of their non-correlation with the purely random component (based on Sargan's test). 


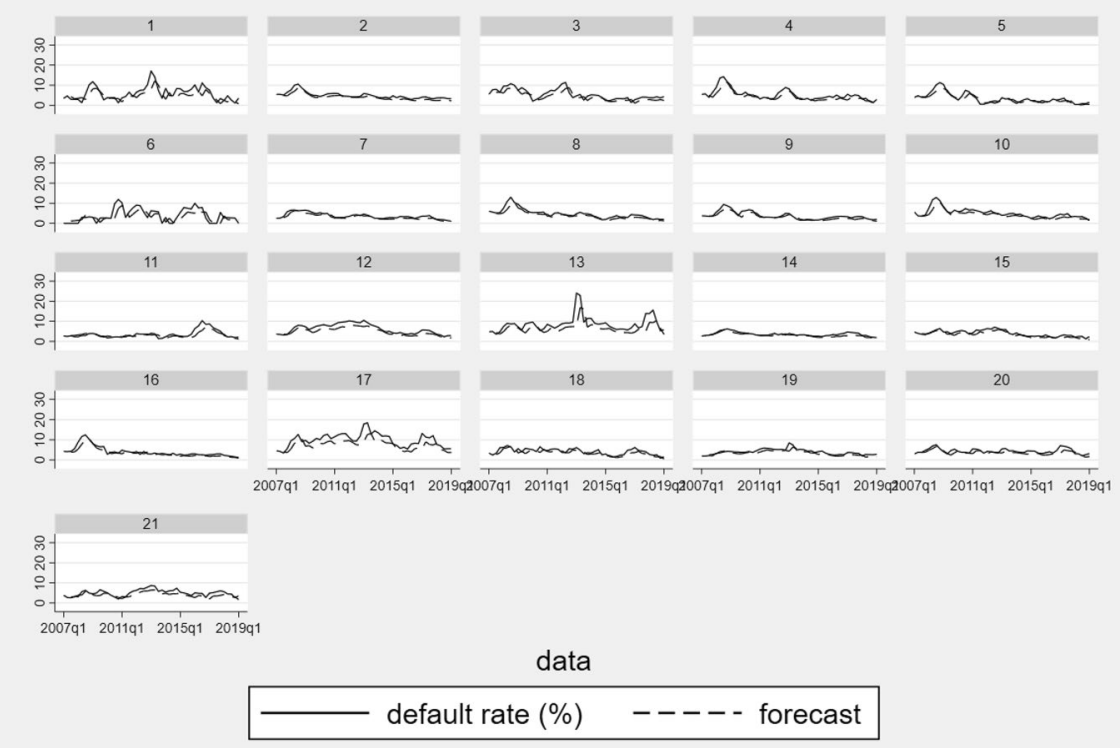

Graphs by activity sector

Fig. 5 Default rates and forecast by sector of activity in the 2007-2019 period

Note: ("1"-Mining and quarrying; "2"-Agri food industries; "3"-Textiles, clothing and footwear; "4"-Wood, paper products and printing; " 5 "-Chemicals industry; " 6 "- Pharmaceuticals industry; "7"-Manufacture of rubber and plastics; "8"-Metallurgy and metalworking; "9"-Metal manufactures; "10"-Energy, water and waste; "11"-Other of manufacture; "12"-Construction; "13"-Motor vehicles trade; "14"-Wholesale trade; "15"-Retail trade; "16"- Transportation and storage; "17"Accommodation and food service activities; "18"-Information and communication; "19"-Real estate activities; "20"- Professional, scientific, technical, administration and support service activities, "21"Others)

Source: authors own elaboration

The annual default rate in circumstances of asymmetry, e.g. by activity across the non-financial corporations sector proved to be in line with the macroeconomic baseline scenario. Variables proving statistically significant in explaining corporate default rate are: (1) annual GDP growth; (2) annual inflation rate; (3) nominal interest rate; and (4) change in the real effective exchange rate (REER). The model specification that includes these variables is characterized by the smallest root-meansquare error (RMSE).

The results of the forecasts carried out are as presented in Fig. 5.

\subsection{Results from the micro stress test}

The results of the research take the form of forecast default rates (DR) and probability of default (PD) in the annual horizon, for June 2020. The two scenarios considered in this respect were a baseline one for the state that would be present were there 


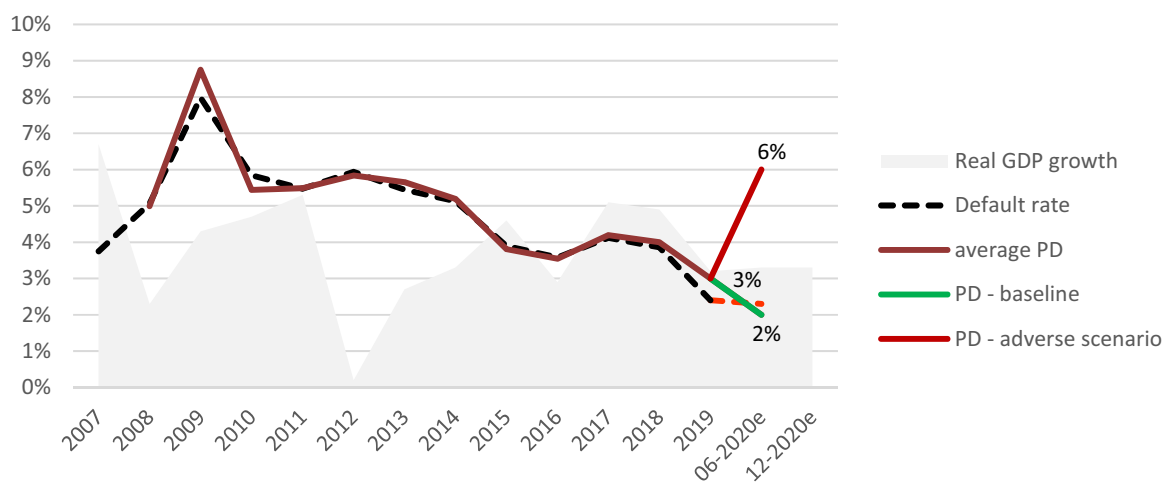

Fig. 6 Forecast default rate and probability of default (PD)_June 2020

Source: authors own elaboration

to be no impact of COVID-19; as well as an adverse one that takes the impact of the pandemic into account.

With default-rate forecasting under the baseline scenario, the assumption was of 2020 GDP growth in line with National Bank of Poland forecasts presented in the current inflation and GDP projection report (as published on 9 March 2020). The value in this case is $3.2 \%$. In turn, the assumption of a significant impact of COVID-19 on the economy leads to expectations that growth in the Polish economy will slow to about $1.5 \%$ (still an optimistic scenario). In Poland, as in Europe as a whole, recovery should look more U-shaped, with a decline in activity in the form of 2 quarters (quarters 2 and 3), with it already being possible to talk about economic growth in Q4 of 2020.

With the negative scenario, forecasting of probability of default proceeded on the assumption that enterprises operated as they had a year before for the 8 months between June 2019 and February 2020, only to succumb to one or other of the scenarios indicated in Table 2 between March and June of 2020.

Using the macroeconomic module and the base scenario, the default rate for June 2020 was anticipated to be at a level of $2.3 \%$ (Fig. 6). The probability of default obtained using the microeconomic module was in turn $2 \%$.

Under the negative scenario, the contention was that, within the space of a year, the forecast regarding default probability indicates possible deterioration of debt-servicing capacity among companies with outstanding bank loans, in the context of further tensions related to COVID-19. Compared with the current default rate $(2.4 \%$ as at the end of December 2019), estimates indicate a rise to 6\% (June 2020).

Figure 7 presents enterprise rating classes (where 0 is the best rating class and 9 the worst) in line with the base and negative scenarios. Under the negative scenario, the distribution dominant was moved from class $3(\mathrm{PD}<0.4 \%)$ to class 7 (PD $<6.4 \%$ ). In analyzing the transition matrix for ratings assigned to companies on the basis of the two scenarios, it was noted that this deteriorated in $90 \%$ of all enterprises. 

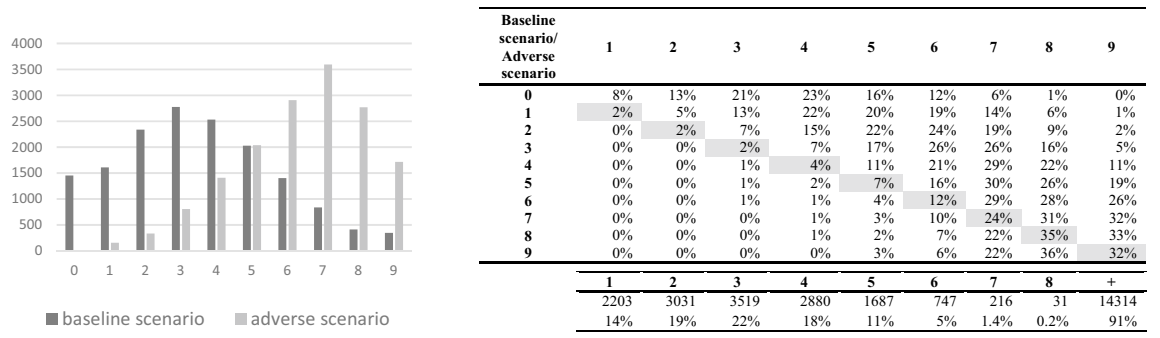

Fig. 7 Enterprise rating and matrix for migration between states-June 2020

Source: authors own elaboration

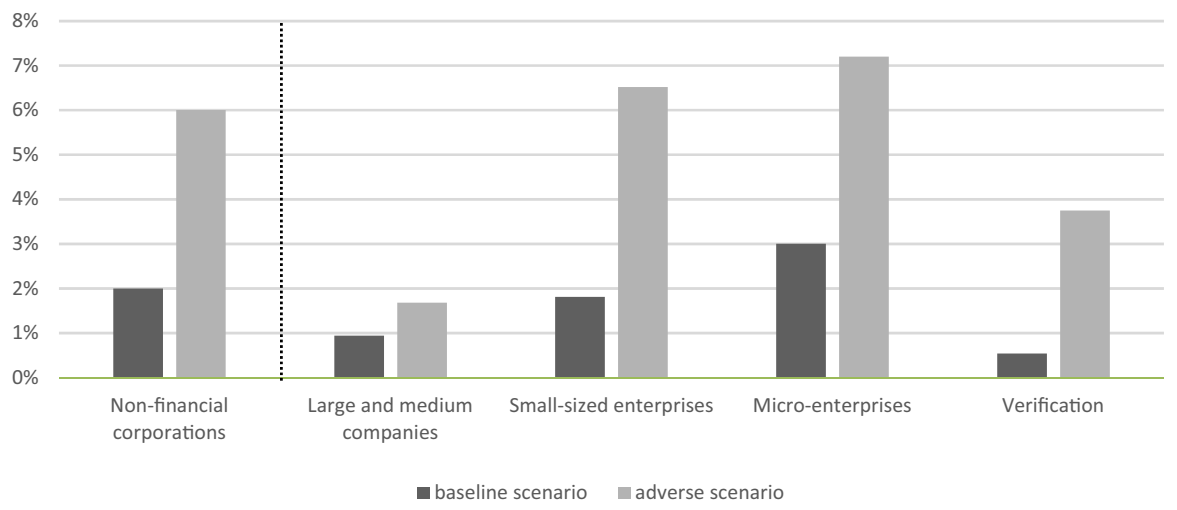

Fig. 8 Forecast probability of default (PD) for June 2020, by company size Source: authors own elaboration

Depending on the size of the company, the quality of loan portfolios will deteriorate on bank balance sheets in all segments (Fig. 8), where the scenario is the negative one. Among large and medium-sized enterprises, the probability of default increases 1.5-fold, while with small ones the corresponding figure is more than threefold.

Where the scenario is the baseline one, micro-enterprises are seen to have the highest probability of default. Risk indicators like probability of default or debt level in particular affect non-financial enterprises' likelihood of gaining access to finance, especially where they are in the small or micro categories. In essence, the probability of default is a good indicator of a company's ability to obtain a loan. And an adequate level of solvency is a necessary pre-condition for such a loan to be taken out. In this context, companies perceive access to finance as important when a poor financial situation is being reported. However, as loans from credit institutions are being taken out, it is necessary for financial equilibrium at the company level to be maintained, with over-indebtedness avoided, an adequate level of liquidity assured, and management and use of publicly-available resources efficient. Economic growth should also be of a sustainable nature. 


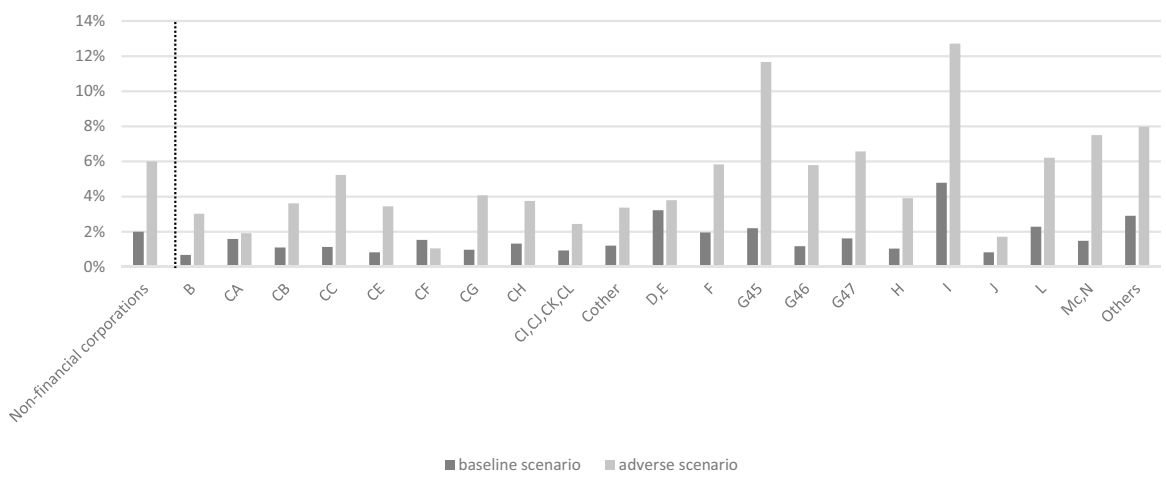

Fig. 9 Probability of default by business section/subsection-June 2020 Source: authors own elaboration

Figure 9 shows the probability of enterprises defaulting in individual sections/ subsections of their operations. In general, the probability of default over a 12-month horizon is higher for companies with a low level of technology (e.g. trading) than for medium and high-tech companies. This points to the higher level of creditworthiness of technology-intensive companies. Thus, the current pattern of economic growth might be improved, should there be more-explicit orientation towards these sectors by credit institutions. Under the baseline scenario, the highest probability of default in the analyzed enterprises (for which total commitment over PLN 2 million was assumed) characterizes those that deal with accommodation and catering (5\%), energy and municipal services (3\%), and other services (3\%). For oil and gas companies, 2020 will prove particularly difficult where financial problems have anyway accumulated in recent years. Demand for petroleum raw materials is decreasing, while supply remains high. Given this imbalance, we can expect the average price of oil to fall, bringing with it intensifying credit risk in the sector, and a worsening of the business climate.

The observation with the negative scenario is that almost all industries will feel the impact of COVID-19. The highest PD level is found for companies dealing with accommodation and catering (13\%), trade in motor vehicles (12\%), other services (such as activities related to culture, entertainment and recreation) (8\%), business services (8\%) and trade retail and wholesale (6-7\%). The commercial sector, as well as transport and services, are victims of the pandemic. While transport shows $\mathrm{PD}=4 \%$ for now, upcoming months will see values for that indicator increase. In addition, most industrial subsections will suffer (excluding the agri-food industry, in which the increases in the probability of default are slight).

The pertinent question does not therefore concern which market sectors will suffer particularly severely, but rather which (for one reason or another) will suffer somewhat less. The pharmaceuticals industry is likely to benefit significantly from the current situation; as is the aforementioned case of the agri-food industry. It is also worth noting how the impact of COVID-19 will be more limited where the information and communications industry among service companies is concerned. 


\section{Conclusion}

This paper relates to the building of a macro-prudential tool assessing whether the banking sector is properly prepared to deal with losses arising from the development of the enterprise sector, in an orderly fashion, under certain macroeconomic scenarios. The tool was designed in two stages. First, the logit probability of default (PD) was modeled for the corporate sector one year in advance, using micro data, as defined by the default Basel II standard, via a bottom-up approach. Second, the PD model was combined with a macroeconomic module to capture the effects of macroeconomic-position feedback in the banking sector, by way of the corporate-sector channel. Models of this kind help with the assessment of financial stability thanks to a tripartite approach that: (1) shows the main microeconomic factors best explaining companies' behavior in the servicing of bank debt; (2) indicates the level and direction of credit risk existing currently in a bank's portfolio-in a specified time horizon (the most common time range is PD for the next year); and (3) provides a stress-testing framework that investigates the impact of COVID-19 scenarios on the probability of default of non-financial companies (the new micro stress-test).

For Poland, the economic consequences of the COVID-19 pandemic will be profound and serious. The pandemic is already offering the Polish economy a real stress test. And even the resumption of economic activity does not necessarily denote rapid recovery in the true sense.

The main purpose of this article has been to provide a stress-testing framework that investigates the impact of COVID-19 scenarios on the probability of default among non-financial companies (as a new micro stress-test). In line with its scenario, most economic activity in Poland was to be frozen through to the end of June.

The pandemic crisis and associated massive "lockdowns" hit all major sectors of the domestic economy hard. Amid the threat of bankruptcy of large companies, micro, small and medium-sized enterprises run the risk of not resuming 
their work even after quarantine measures are canceled. In a manner conditioned by company size, the quality of loan portfolios will deteriorate in the balance sheets of banks in all segments. Where the negative tested scenario is concerned, the probability of default among large and medium-sized enterprises increases 1.5-fold, while among small companies the corresponding increase is a threefold one. The highest PD level characterizes companies dealing in accommodation and catering, the trade in motor vehicles, other services (such as activities related to culture, entertainment and recreation), business services, and retail and wholesale trading. However, there are certain sectors that can even increase profits and strengthen their market position in these difficult times.

Equally, the credit risk faced by business will be high in even the best-case scenario-that is where the third quarter sees the global economy beginning to recover gradually, with avoidance of a second wave of COVID-19 following the lifting of strict quarantine measures.

Otherwise, the recession will be a deep and long one, with the increase in corporate indebtedness large enough to raise concerns about the solvency of business entities. In such conditions, much organizational innovation will be needed if human and capital resources are to kept ready for a restart of the economy. This is feasible for Poland, but will still represent the most major challenge faced by the country since the days of its systemic transformation. Let us therefore assume that the scenario in question is more of a "reserve" one.

\section{Appendix}

See Table 7. 


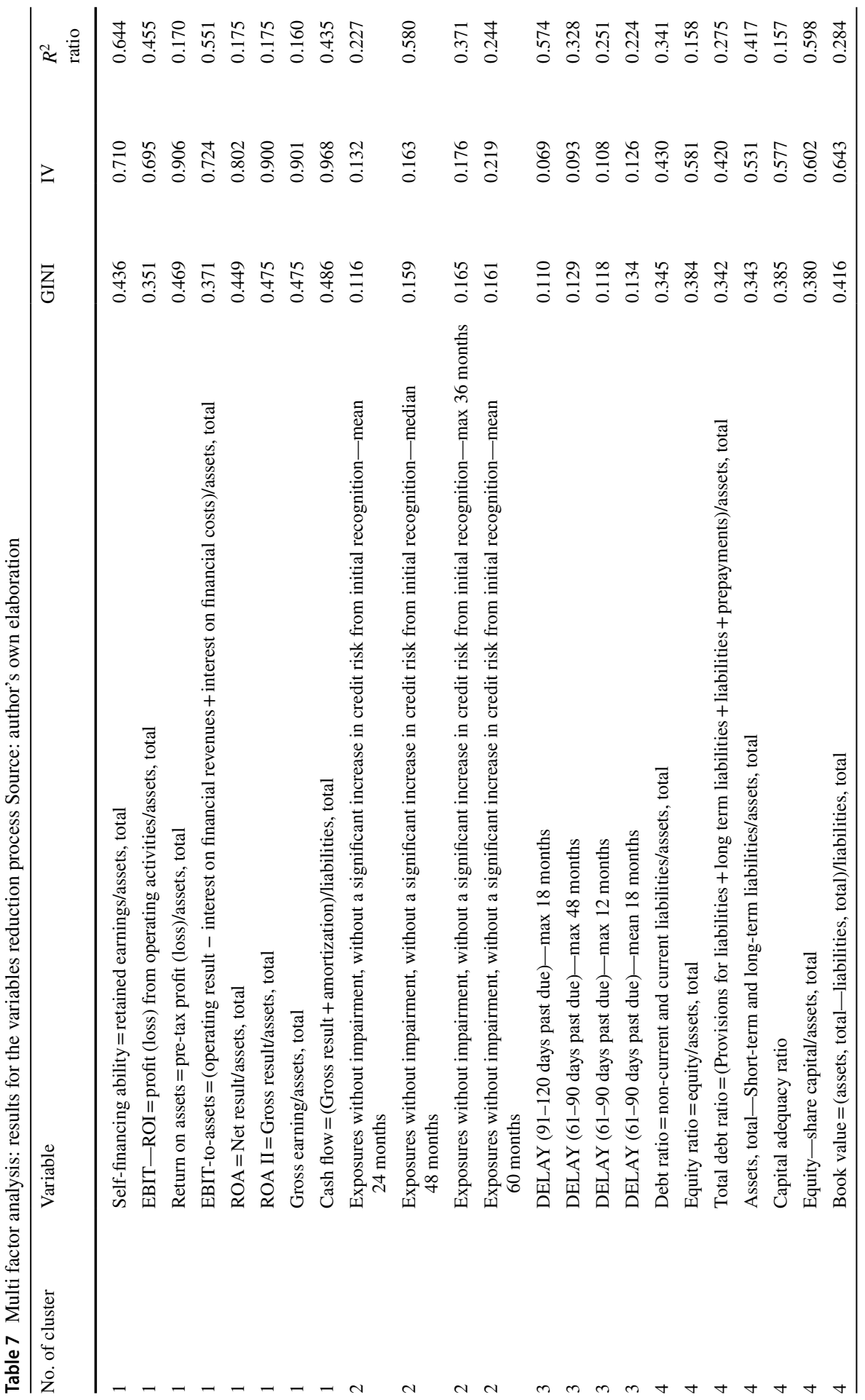




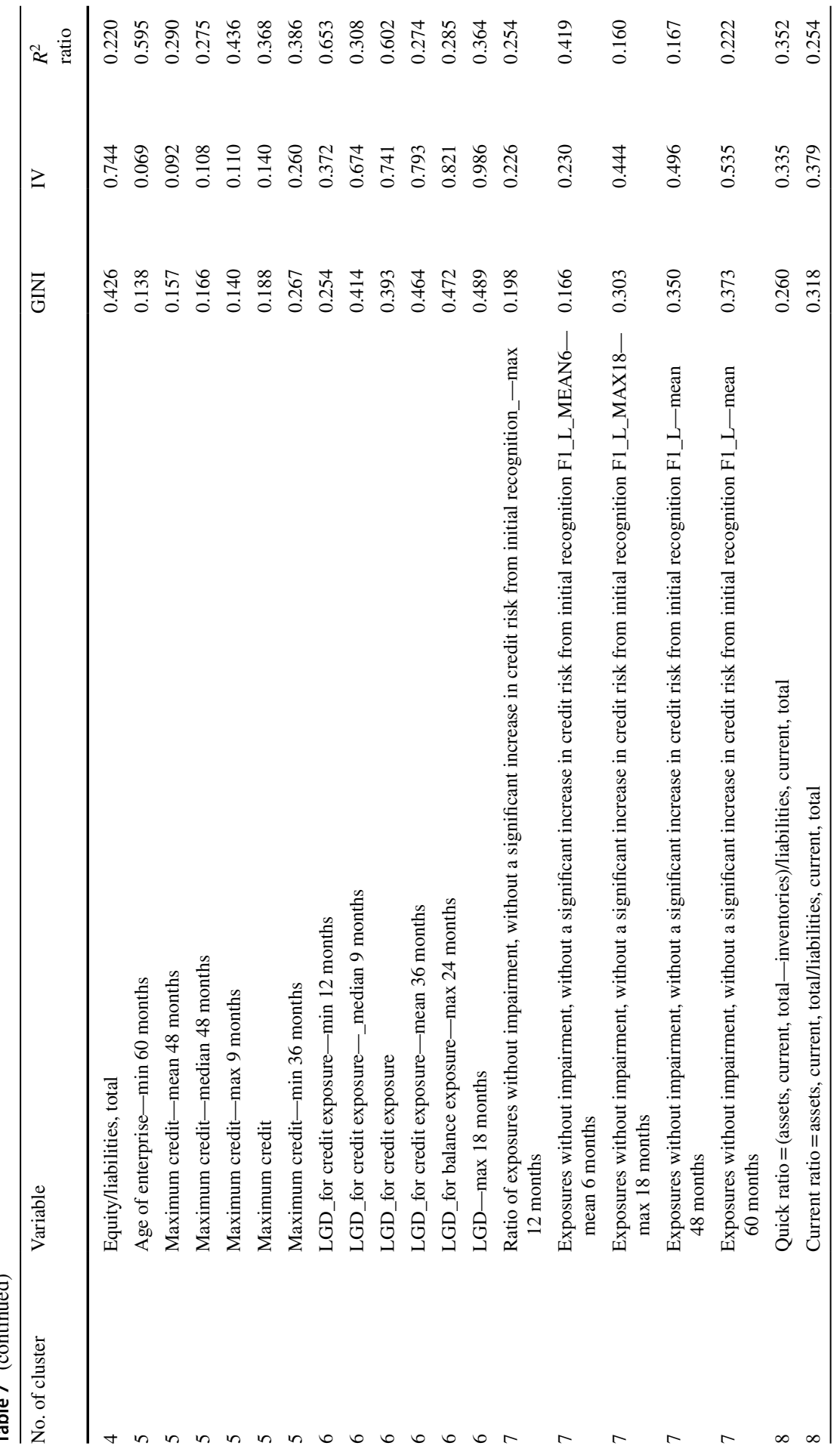




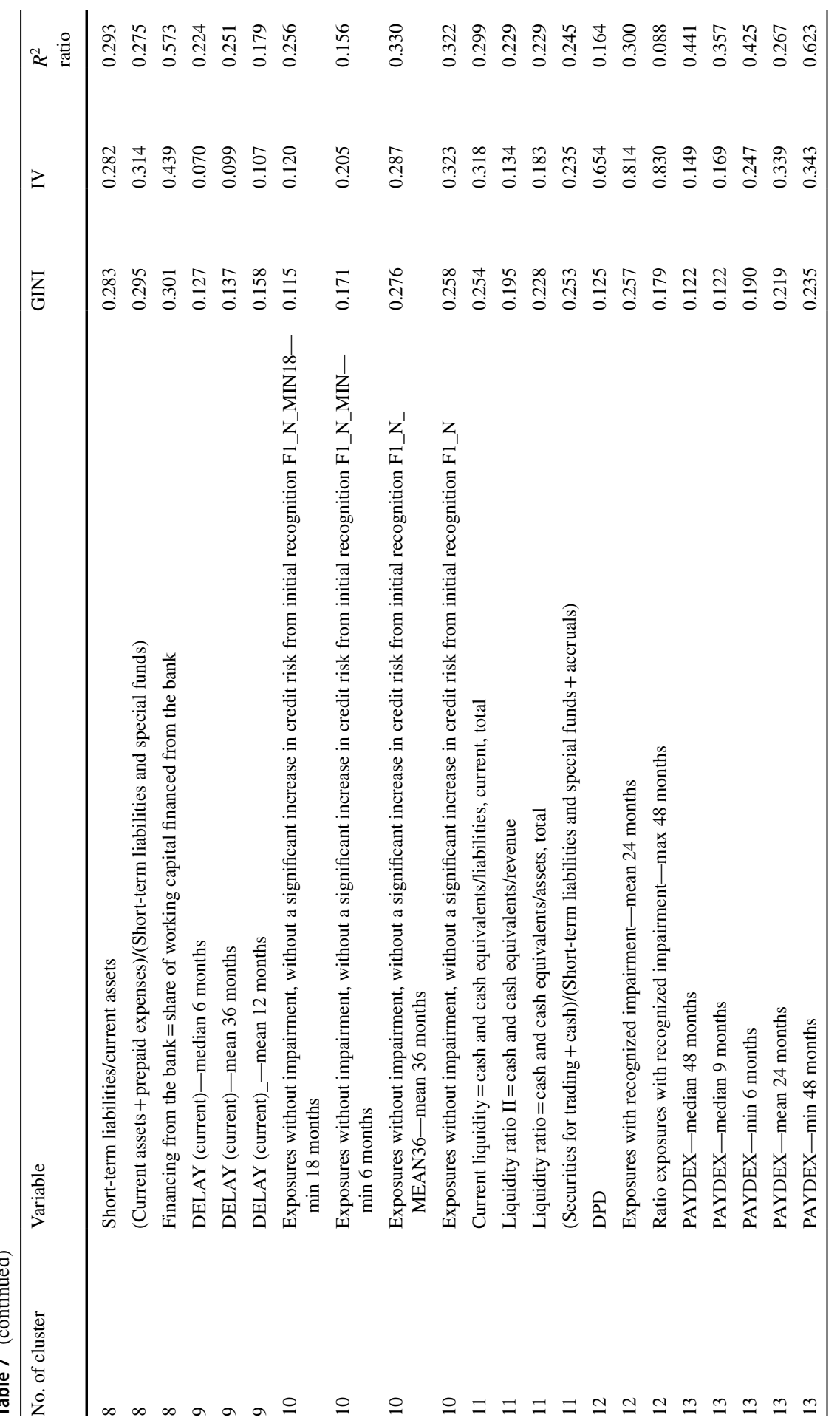




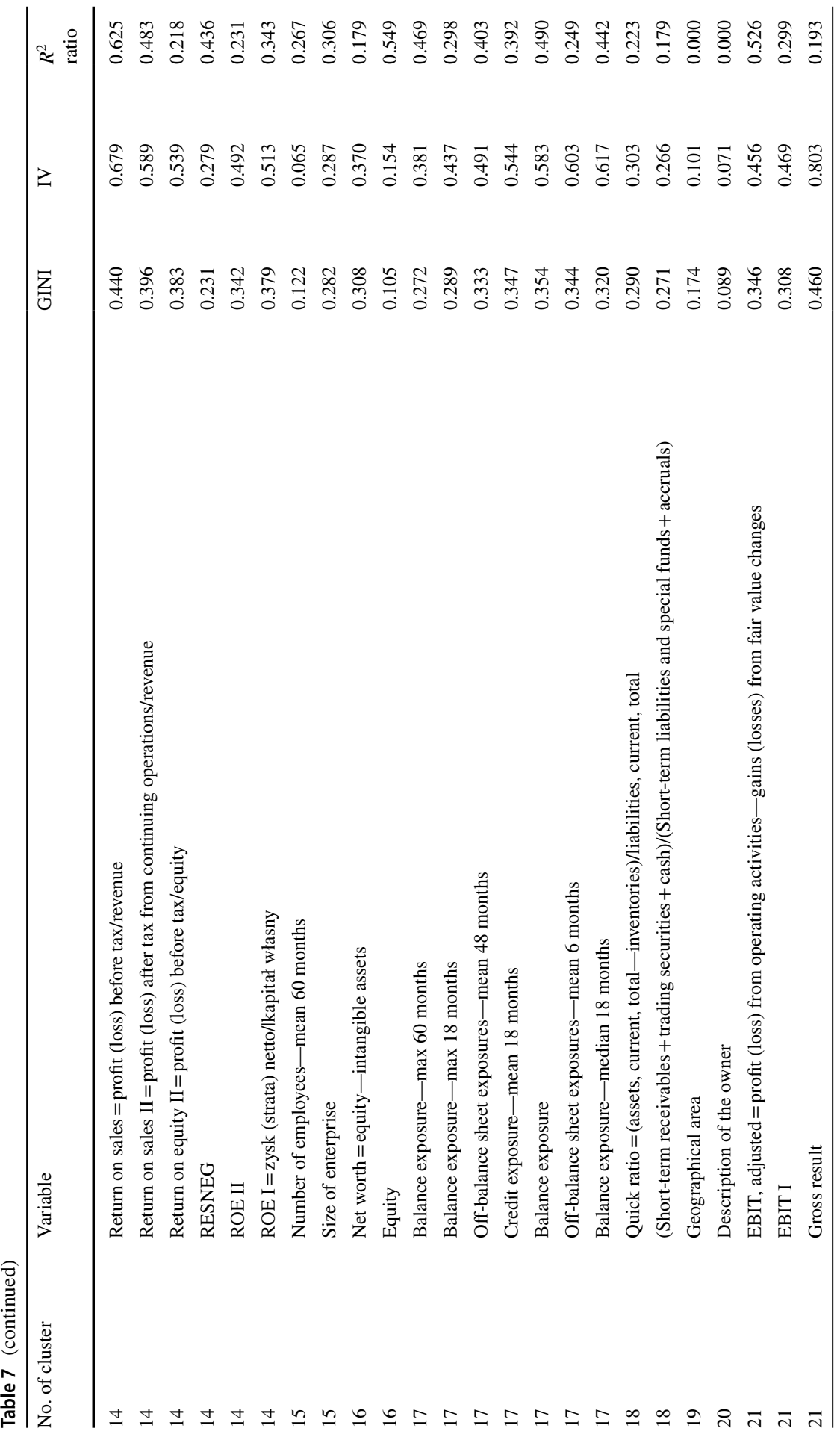




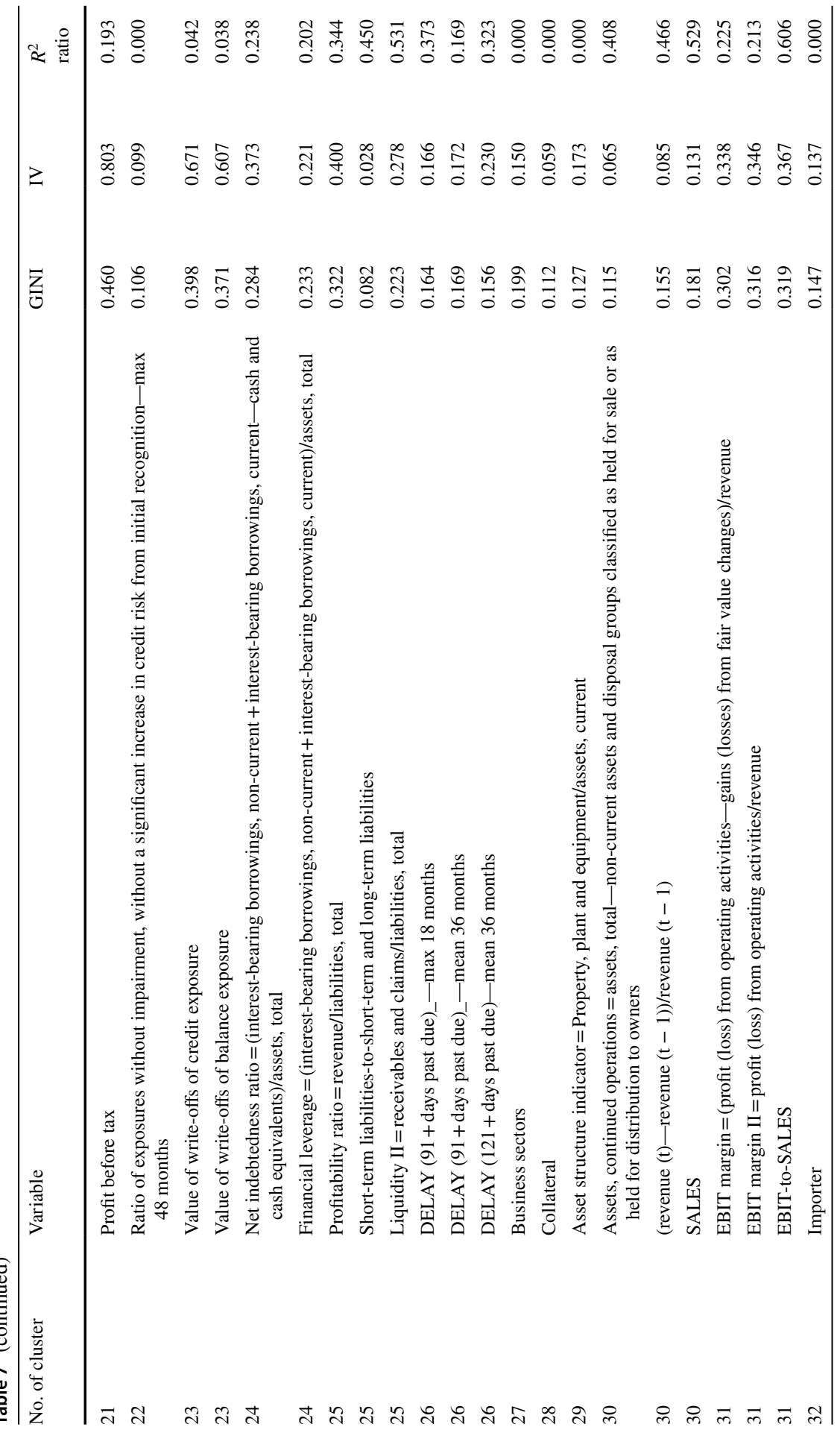




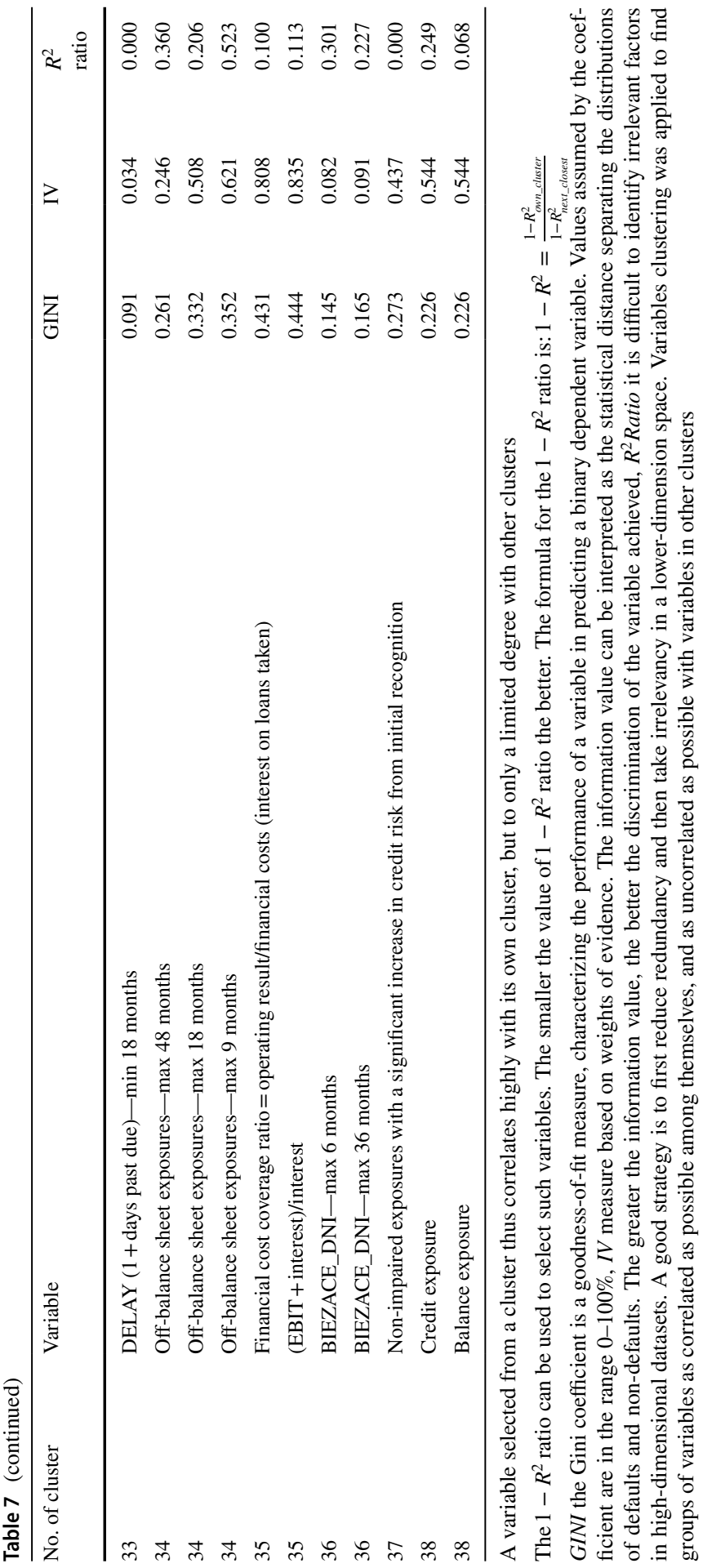




\section{References}

Altman, E. (2010). The Z-Metrics ${ }^{\mathrm{TM}}$ methodology for estimating company credit ratings and default risk probabilities. RiskMetrics Group. Retrieved from June 01, 2020. https://www.fdic.gov/regulations/ reform/Altman2.pdf.

Arellano, M. (2004). Panel data econometrics. Oxford: Oxford University Press.

Arellano, M., \& Bond, S. (1991). Some tests of specification for panel data: Monte Carlo evidence and an application to employment equations. The Review of Economic Studies, 58(2), 277-297.

Baltagi, B. H. (2005). Econometric analysis of panel data. Chichester: Wiley.

Bandt, O., Dumontaux, N., Martin, V., Medee, D. (2013). Stress-testing banks' corporate credit portfolio. Debats economiques et financiers, 1. Banque de France. Retrieved from June 01, 2020. https://ideas .repec.org/p/bfr/decfin/1.html.

Basel Committee on Banking Supervision. (2006). International convergence of capital measurement and capital standards. A revised framework Comprehensive Version. Bank for International Settlements. Retrieved from June 01, 2020. https://www.bis.org/publ/bcbs128.htm.

Basel Committee on Banking Supervision. (2009). Principles for sound stress testing practices and supervision. Bank for International Settlements. Retrieved from June 01, 2020. https://www.bis.org/publ/ bcbs155.htm.

CEBS. (2010). Guidelines on Stress Testing (GL 32). Retrieved from June 01, 2020. https://eba.europ a.eu/regulation-and-policy/supervisory-review-and-evaluation-srep-and-pillar-2/revised-guidelines -on-stress-testing.

Chan-Lau, J. A., Lim, C. H., Rodríguez-Delgado, J. D, Sutton, B. W., \& Tashu, M. (2017). Bottom-up default analysis of corporate solvency risk: An application to Latin America. International Monetary Fund, 17/133. Retrieved from June 01, 2020. https://www.imf.org/en/Publications/WP/Issue s/2017/06/08/Bottom-Up-Default-Analysis-of-Corporate-Solvency-Risk-An-Application-to-Latin -America-44963.

De Servigny, A., \& Renault, O. (2002). Default correlation: empirical evidence. Standard and Poor's, Working Paper. Retrieved from June 01, 2020. https://www.researchgate.net/publication/22867 9968_Default_correlation_Empirical_evidence.

Emmer, S., \& Tasche, D. (2005). Calculating credit risk capital charges with the one-factor model. Journal of Risk, 7(2), 85-101.

Heppe, B. (2014). Should stress test models be country specific? Why UK banks would fail the 2014 tests based on Spanish models. Open Source Investor Services B. V. (OSIS).

International Monetary Fund (2003). Compilation Guide on Financial Soundness Indicators, March draft (Washington: International Monetary Fund). http://www.imf.org/external/np/sta/fsi/eng/guide/index .htm

Jakubik, P., \& Schmieder, C. (2008). Stress Testing Credit Risk: Comparison of the Czech Republic and Germany. FSI Award 2008 Winning Paper. Financial Stability Inst., Bank for International Settlements. Retrieved from June 01, 2020. https://www.bis.org/fsi/awp2008.pdf.

Jiménez, G., \& Javier, M. (2007). Modelling the distribution of credit losses with observable and latent factors. Journal of Empirical Finance., 16(2), 235-253.

Jones, M., Hilbers, P., \& Slack, G. (2004). Stress testing financial systems: What to do when the governor calls. 04/127. International Monetary Fund. Retrieved from June 01, 2020. https://www.imf.org/ external/pubs/ft/wp/2004/wp04127.pdf.

King, G., \& Zeng, L. (2001). Logistic regression in rare events data. Political Analysis, 9(2), 137-163.

Merton, R. C. (1974). On the pricing of corporate debt: the risk structure of interest rates. The Journal of Finance, 29(2), 449-470

Polish Financial Supervision Authority (2009). Wykorzystanie testów stresu w procesie nadzoru nad zakładami ubezpieczeń. KNF. Retrieved from June 01, 2020. http://www.kalkulator-ubezpiecze niowy.pl/wykorzystanie_testow_raport.pdf

Polish Financial Supervision Authority (2013a). Rekomendacja S. dotycząca dobrych praktyk w zakresie zarządzania ekspozycjami kredytowymi zabezpieczonymi hipotecznie. KNF. Retrieved from June 01, 2020. https://www.knf.gov.pl/knf/pl/komponenty/img/rekomendacja_s_8566.pdf

Polish Financial Supervision Authority (2013b). Rekomendacja T. dotycząca dobrych praktyk w zakresie zarządzania ryzykiem. KNF. Retrieved from June 01, 2020. https://www.knf.gov.pl/knf/pl/kompo nenty/img/Rekomendacja_T_\%2814_09_2018\%29_63160.pdf

Mátyás, L., \& Sevestre, P. (2008). The econometrics of panel data. Berlin: Springer. 
Nehrebecka, N. (2016). Approach to the assessment of credit risk for non-financial corporations. Evidence from Poland, IFC Bulletins chapters, in: Bank for International Settlements (ed.), Combining micro and macro data for financial stability analysis, 41, Bank for International Settlements. Retrieved from June 01, 2020. https://www.bis.org/ifc/publ/ifcb41q.pdf.

Schmieder, C., Claus, P., \& Maher, H. (2011). Next generation balance sheet stress testing. 11-83. International Monetary Fund. Retrieved from June 01, 2020. https://www.imf.org/external/pubs/ft/ wp/2011/wp1183.pdf.

Tasche, D. (2003). A traffic lights approach to PD validation. Deutsche Bundesbank Discussion Paper. Retrieved from June 01, 2020. https://pdfs.semanticscholar.org/efda/f4f38d0c294051c6df547a429 227fa63dfe3.pdf.

Virolainen, K. (2004). Macro stress testing with a macroeconomic credit risk model for Finland. Bank of Finland Discussion Papers. 18/2004. Retrieved from June 01, 2020. https://papers.ssrn.com/sol3/ papers.cfm?abstract_id=622682.

Wilson, T. (1997a). Portfolio credit risk (I). Risk, 10(9), 56-61.

Wilson, T. (1997b). Portfolio credit risk (II). Risk, 10(10), 111-117.

Yurdakul, F. (2014). Macroeconomic modelling of credit risk for banks. Procedia-Social and Behavioral Sciences, 109(8), 784-793.

Publisher's Note Springer Nature remains neutral with regard to jurisdictional claims in published maps and institutional affiliations. 